\title{
Numerical simulation of pool boiling on smooth, vertically aligned tandem tubes
}

\author{
S. M. A. Noori Rahim Abadi ${ }^{* 1}$, A. Ahmadpour ${ }^{2}$, J. P. Meyer ${ }^{1}$ \\ ${ }^{1}$ Department of Mechanical and Aeronautical Engineering, University of Pretoria, Pretoria, \\ South Africa \\ ${ }^{2}$ Department of Mechanical Engineering, Amirkabir University of Technology, Tehran, Iran
}

\section{Research highlights}

- 3D numerical simulation of nucleate pool boiling in atmospheric pressure

- Superior heat transfer capacity of water in contrast with ethanol and FC-72

- Heat transfer coefficient decreases with increase of the tube inclination angle

- Optimum inclination angle is found to be $30^{\circ}$ for the specified operating conditions

\begin{abstract}
:
In the present study, a numerical simulation of atmospheric pool boiling on tandem, inclined, electrically heated circular tubes is performed. An Eulerian-Eulerian description of the two-phase flow formulations is adopted together with a Rensselaer Polytechnic Institute (RPI) nucleate boiling model to account for the heat and mass transfer in the boiling phenomenon. The pool boiling is studied in the range of 0 to $100 \mathrm{~kW} / \mathrm{m}^{2}$ for the heat flux and for inclination angles of 0 to $90^{\circ}$. The effect of the boiling liquid characteristics on the key features of the pool boiling phenomenon is studied, as well as using water, ethanol and FC-72 as the working fluid. The
\end{abstract}


numerical results are validated against available experimental measurements, and the effects of the inclination angle, working fluid and magnitude of the heat flux are explored thoroughly.

Keywords: Pool boiling, Eulerian-Eulerian, RPI model, Inclination angle.

*Corresponding author's email: ali.abadi@up.ac.za;

Tel: +27728035548

\section{Nomenclature:}

$\mathrm{A}_{b} \quad$ Part of the wall surface covered by nucleate bubbles $\left[\mathrm{m}^{2}\right]$

$A_{\text {interfacial } \quad \text { Interfacial area }\left[\mathrm{m}^{2}\right]}$

$C_{D} \quad$ Drag coefficient [-]

$C_{L} \quad$ Lift coefficient [-]

$C_{p} \quad$ Specific heat $[\mathrm{J} / \mathrm{kgK}]$

$d \quad$ Bubble diameter [m]

$D_{w} \quad$ Bubble departure diameter [m]

Eo Eotvos number [-]

F $\quad$ Force [N]

$g \quad$ Gravitational acceleration $\left[\mathrm{m} / \mathrm{s}^{2}\right]$

$h \quad$ Fluid specific enthalpy $[\mathrm{J} / \mathrm{kg}]$

$h_{b} \quad$ Boiling heat transfer coefficient $\left[\mathrm{W} / \mathrm{m}^{2} \mathrm{~K}\right]$

$h_{l v} \quad$ Latent heat of evaporation $[\mathrm{J} / \mathrm{kg}]$

$h_{c} \quad$ Single-phase heat transfer coefficient $\left[\mathrm{W} / \mathrm{m}^{2} \mathrm{~K}\right]$ 


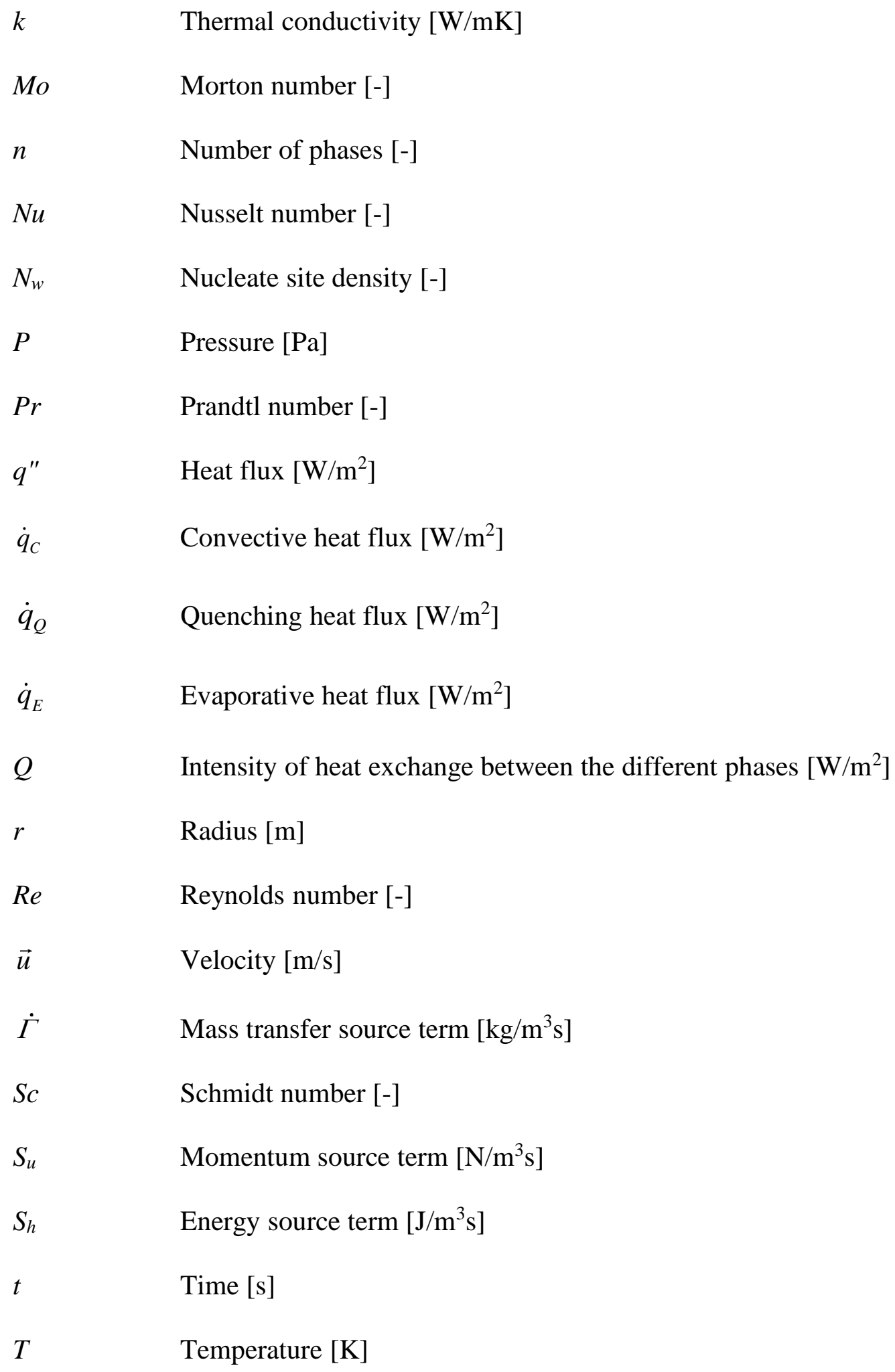




$\begin{array}{ll}\alpha & \text { Volume fraction }[-] \\ \rho & \text { Density }\left[\mathrm{kg} / \mathrm{m}^{3}\right] \\ \mu & \text { Dynamic viscosity }[\mathrm{Pa} . \mathrm{s}] \\ k & \text { Turbulent kinetic energy }\left[\mathrm{m}^{2} / \mathrm{s}^{2}\right] \\ \varepsilon & \text { Turbulent energy dissipation rate }\left[\mathrm{m}^{2} / \mathrm{s}^{3}\right] \\ \Omega & \text { Mean rate of rotation tensor }[1 / \mathrm{s}] \\ \sigma & \text { Surface tension }[\mathrm{N} / \mathrm{m}] \\ \delta t & \text { Time scale in boiling model }[\mathrm{s}] \\ \theta & \text { Tube inclination angle }[\mathrm{deg}]\end{array}$

\section{Subscripts}

$\begin{array}{ll}b & \text { Bubble } \\ p & \text { Phase index } \\ k & \text { Phase index } \\ l & \text { Liquid } \\ l v & \text { Liquid-vapour } \\ L & \text { Laminar } \\ m & \text { Mixture } \\ s a t & \text { Saturation } \\ T & \text { Turbulent } \\ v & \text { Vapour } \\ v, m & \text { Virtual mass } \\ w & \text { Wall }\end{array}$




\section{Introduction}

Boiling heat transfer from tubes and tube bundles is an important research area in the multiphase flow and heat transfer fields [1]. Investigations are prompted by the need to understand the boiling mechanism, a key factor in the design of various industrial heat exchangers widely used in power generation and petrochemical plants. In the absence of forced fluid motion, in which the heat transfer coefficient is related to the temperature difference between the inlet and outlet flows and surface heat flux, pool boiling occurs on a heated surface and has its own applications in passive heat exchangers for nuclear reactors, flooded type evaporators and thermosyphon reboilers $[2,3]$.

Pool boiling on a tube or a tube bundle is a complex physical phenomenon that is affected by the thermophysical properties of the working fluid, the quality of the pipe surface, and the tube bundle arrangement, i.e., the tube's pitch and inclination or elevation angle [2]. Experimental measurements have been the primary tool for studying this phase-change phenomenon. A comprehensive experimental database containing pool boiling data from single electrically heated circular tube (submerged in a pool of boiling fluid) with various boiling fluids and tube surface qualities is provided by Stephan and Abdelsalam [4], Gorenflo [5]. Proper correlations for pool boiling on a heated tube bundle were introduced to represent the experimental data by Aprin et al. [6]. They considered different pure hydrocarbons such as n-pentane, propane and iso-butane under several operating conditions (pressure, heat flux and mass flow rate). Two different flow regimes, bubbly and dispersed flow patterns, were distinguished within the experimentations. They showed that in the bubbly flow regime the heat transfer coefficient depended only on heat flux and reduced pressure, but in the dispersed flow regime its hydrodynamic parameters such as vapour velocity 
and the Reynolds number based on vapour properties played the dominant role. Finally, proper correlations were proposed for each considered two phase flow regime.

Gorgy and Eckels [7] experimentally determined the local heat transfer coefficient for R-134a pool boiling on smooth and enhanced tubes. The heat flux needed to induce pool boiling was provided by warm water flowing inside the tubes. For the enhanced tube, two distinctive regions were detected in the pool boiling curve. Across the first region, the heat transfer coefficient rises sharply with heat flux. In the second region, the heat transfer coefficient is (approximately) independent of the heat flux; as a result, both regions of the pool boiling curve could be accurately modelled using a proper power law model.

In another works, Chien and Webb $[8,9]$ investigated the effect of geometrical parameters on the boiling heat transfer coefficient in "tunnelled" enhanced boiling surfaces. Tests were performed on a 19.1-mm diameter horizontal tube and pore diameters of $0.12,0.18,0.23$, and $0.28 \mathrm{~mm}$ and the pore pitches of $0.75,1.5$, and $3.0 \mathrm{~mm}$, using different refrigerants such as R11 and R123 at $26.7^{\circ} \mathrm{C}$ for heat fluxes from 2 to $70 \mathrm{~kW} / \mathrm{m}^{2}$. The results showed that the boiling heat transfer coefficient increased with increasing tunnel height and decreasing of the tunnel pitch. Moreover they found that sharp tunnel corners provided greater enhancement for heat transfer rates.

Gupta et al. [10] experimentally determined the local pool boiling heat transfer coefficient for a staggered bundle of vertical tubes. The local heat transfer coefficient increases along the direction of the nucleated bubbles' flow. Similar measurements in a vertical array of horizontal pipes under flooded condition were determined by Ribatski et al. [11]. Regardless of the tube bundle 
arrangement, a local maximum emerges in the profile of the local heat transfer coefficient, along a vertical direction; the heat transfer rate tends to an asymptotic value beyond this local extrema.

Nucleate pool boiling from a small staggered tube bundle flooded in water, methanol and refrigerant R141b was evaluated via an experiment by Krasowski and Cieslinski [12]. The highest overall heat transfer coefficient was determined for the case of a tube bundle flooded in water and operating under atmospheric conditions. Moreover, these researchers determined that as the pitchto-diameter ratio of the tube bundle increases, the heat transfer coefficient increases as well.

Kang [13] investigated the pool boiling phenomenon on the outside and inside surfaces of a 51 mm horizontal tube. He found that the maximum and the minimum values of the heat transfer coefficients on the outside surface occurred at $\theta=45^{\circ}$ and $180^{\circ}$, respectively. However the minimum value on the inside surface occurred at $\theta=0^{\circ}$. To justify this peculiar behaviour, Kang argued that for the boiling occurred on the outer surface of the circular tube, the liquid agitation and bubble coalescence were the main mechanisms of the pool boiling; in contrast, on the inner surface of the tube, the phase change phenomenon was dominated by micro layer evaporation and liquid agitation.

The effect of the tube bundle pitch on pool boiling was studied by Kang [14] on a pair of stainless steel tubes positioned vertically above each other. In the later work, water was chosen as the working fluid. The study determined that raising the total heat transfer rate weakens the tube bundle effect as the tube pitch increases. Kang extended this work by considering several staggered arrangements for heated tubes [15]; the elevation angle was chosen as the primary variable, and 
its effect was studied on pool boiling heat transfer. Kang determined that the convection heat transfer for the upper tube increases with elevation angle [15].

Kang [16] conducted a comprehensive experimental investigation on pool boiling from an inclined circular tube bundle placed in an atmospheric water tank. The setup consists of two smooth, vertically aligned stainless steel tubes with a diameter of $19 \mathrm{~mm}$ and a length of $400 \mathrm{~mm}$. These tubes submerged in a bath with the height, length and width of $1400 \mathrm{~mm}, 1300 \mathrm{~mm}, 900 \mathrm{~mm}$, respectively [16]. The inclination angle of the tubes $(\theta)$ could be adjusted between $0^{\circ}$ and $90^{\circ}$ in respect to the horizontal direction; both tubes were electrically heated by an adjustable flux of $q_{L}^{\prime \prime}$ for the lower tube and $q_{T}^{\prime \prime}$ for the upper tube. The surface temperature of the upper tube was denoted by $T_{w}$ and was an important variable. The enhancement of heat transfer from the upper tubes (due to the departure of vapour bubbles from the lower tubes which agitates the flow field around the upper tube) is significantly affected by the inclination angle of the tube bundle and the magnitude of the heat flux. The reported elevation in the convective heat transfer coefficient is more pronounced for smaller inclination angles and heat fluxes.

In another work, Ustinov et al. [17] studied the pool boiling heat transfer from tandem tubes with different novel microstructures. The microstructures consisted of copper micro pins upon the tube with the diameter between $0.1 \mu \mathrm{m}$ to $25 \mu \mathrm{m}$, and maximum height of $100 \mu \mathrm{m}$ and maximum density of $10^{9}$ pins $/ \mathrm{cm}^{2}$. They used two refrigerants R134a and FC-3284 as their boiling liquid and they conducted their experiments for two ranges of operating pressures between 5-9 bars and 0.5-1.5 bars. They observed that using microstructured tubes resulted in a significant raise in the pool boiling heat transfer rate compared to the corresponding values for conventional smooth tubes. 
In contrast to well-established, longstanding experimental studies, the numerical simulation of pool boiling on heated surfaces is still in development [18]. A comprehensive survey of relevant scientific literature reveals that two different approaches have been undertaken for the numerical simulation of boiling phase change phenomenon including interface tracking methods and semiempirical flux partitioning methods. In the first approach, use is made of an interface tracking method (e.g. volume of fluid and level set) to capture vapour bubble nucleation, growth and departure form a single or multiple nucleation sites located on a solid heated surface.

In a pioneering numerical simulation of boiling heat transfer with interface tracking methods, Liu et al. [19] modelled the pool boiling of a cryogenic fluid spilled on a flat surface (e.g., ground surface) using the volume of fluid (VOF) method. Eight points located in various regions of the pool boiling curve of nitrogen were chosen for the numerical simulation (including nucleate, transitional and film boiling). The proposed numerical approach under-determined the pool boiling heat flux in the nucleate and transitional boiling regions; however, the film boiling curve was captured reasonably by the numerical scheme. More recently, Sato and Niceno [20] used an interface tracking method to capture the liquid-vapour interface of nucleated bubbles by implementing a colour function within a Computational Fluid Dynamics simulation. Nucleation from multiple active sites on a flat heated surface was considered and the obtained numerical results showed a very good agreement with the experimental data available for the pool boiling of atmospheric water. Furthermore, the temporal evolution of the nucleated bubble shape captured by the numerical simulation is well fitted with the experimental photos of the pool boiling.

In the second approach of the numerical simulation of nucleate boiling, a well-tuned semiempirical formulation is employed to model boiling heat transfer from a solid surface. This boiling 
heat flux is commonly partitioned to multiple components accounting for heat transfer during phase change phenomenon and convective heat transfer during bubble nucleation, growth and departure. As an example, Xiaobin et al. [21] used a multi-fluid formulation associated with the flux partitioning Rensselaer Polytechnic Institute (RPI) boiling model to simulate the pool boiling from a flat, heated surface, submerged in a pool of liquid nitrogen. The numerical results were in good agreement with the experimental boiling curve.

Gu et al.[22] performed extensive CFD simulation of flow boiling using the RPI boiling model. They examined different closure models in the RPI model to achieve the most accurate solution compared to experimental data. They concluded that the best closure model would be the combination of correlations of Lemmert and Chawla [23], Unal [24] and Cole [25] for the calculation of nucleation site density, bubble departure diameter and bubble departure frequency respectively.

A major obstacle which fiercely limited the progress of numerical modelling of pool boiling phenomenon is the lack of universal closure laws and correlations for accurately simulating the physics of boiling heat transfer phenomenon for a wide range of operating conditions. This could be attributed to the large set of influential physical parameters during pool boiling phase change phenomenon, as it was brilliantly stated by Mohanty and Das [26] in their extensive literature survey. They confirmed that the boiling heat transfer is governed by various bubble dynamics parameters such as bubble departure diameter, active nucleation site density, bubble waiting period, bubble growth period, bubble growth rate, bubble departure frequency, thermo-physical properties of the boiling fluid, heat flux, liquid sub-cooling, wall superheat, contact angle, gravity, 
cavity spacing and the operating pressure. They also concluded that the bubble departure diameter, active nucleation site density and departure frequency are the dominant parameters in bubble dynamics as compared to the other parameters during pool boiling phase change.

Due to this complex nature of pool boiling, different conclusions have been made for pool boiling heat transfer in various operating conditions. For instance, Minocha et. al [27] used CFD technique to simulate the pool boiling phenomenon on an inclined tube and found that the optimum inclination angle is $75^{\circ}$, however in another work, Noori Rahim Rahim Abadi and Meyer [28] concluded that there will be a region between $30^{\circ}$ to $60^{\circ}$ for the inclination angle. In the experimental work of Kang [16], which is selected as the base database for the present work the optimum inclination angle was found to be $30^{\circ}$. Therefore, for tackling a particular physical problem involving the boiling heat transfer, the appropriate conservation laws should be utilized and proper values for relevant physical parameters should be adjusted in order to achieve accurate predictions for pool boiling heat transfer rates.

Despite previous efforts for the numerical investigations of pool boiling (some of them cited above), to the best of our knowledge, no attempt has been reported for the numerical simulation of the pool boiling over tube bundles. Therefore, in the present work, numerical simulations of pool boiling phenomenon over smooth inclined tandem tubes that were aligned vertically were performed and the results were validated with the available experimental data. This would be a prominent step towards the numerical simulation of pool boiling from tube bundles flooded in a bath of boiling fluid. Furthermore the conclusions of extensive CFD simulations of Gu et al. [19] were applied to accurate closures in the RPI boiling model. Finally, the effect of working fluid, 
saturation temperature and tube orientation have been investigated on the pool boiling heat transfer for the first time.

Choosing a flux partitioning method over an interface tracking method for the present work can be justified as the use of interface tracking methods for boiling simulations is limited to the study of bubble formation and departure from a single or limited number of bubble nucleation sites and it cannot be extended to real applications due to its exorbitant computational costs for tracking bubble evolution from numerous sites on heated surfaces [28-31]. In contrast, if a flux partitioning method is adjusted properly, it will produce reliable prediction of boiling heat transfer coefficient without any need for the highly accurate tracking of vapour-liquid interfaces. The manuscript was organised as follows: the governing equations of the problem were presented in Section 2, followed by a detailed description of the numerical method. The numerical solution was presented and discussed in Section 3, and the work was concluded by presenting the highlights of the major findings.

\section{Mathematical Formulation}

\subsection{Eulerian-Eulerian approach}

To model pool boiling on smooth tubes, which are inherently a two-phase flow with phase change, the Eulerian-Eulerian framework is adopted such that each phase is treated as a continuum. In the Eulerian-Eulerian method, mass, momentum and energy conservation equations are given as follows for each phase [32-34]:

$\frac{\partial}{\partial t}\left(\alpha^{k} \rho^{k}\right)+\nabla \cdot\left(\alpha^{k} \rho^{k} \vec{u}^{k}\right)=\dot{\Gamma}^{k p}-\dot{\Gamma}^{p k}$ 


$$
\begin{aligned}
& \frac{\partial}{\partial t}\left(\alpha^{k} \rho^{k} \vec{u}^{k}\right)+\nabla \cdot\left(\alpha^{k} \rho^{k} \vec{u}^{k} \vec{u}^{k}\right)=-\alpha^{k} \nabla P+\nabla \cdot \tau^{k}+\alpha^{k} \rho^{k} \vec{g}+\dot{\Gamma}^{p k} \vec{u}^{k}-\dot{\Gamma}^{k p} \vec{u}^{k}+S_{u}{ }^{k} \\
& \frac{\partial}{\partial t}\left(\alpha^{k} \rho^{k} h^{k}\right)+\nabla \cdot\left(\alpha^{k} \rho^{k} \vec{u}^{k} h^{k}\right)=\alpha^{k} \frac{\partial P}{\partial t}+\nabla \cdot q^{k}+Q^{\text {exchange, }, p k}+\dot{\Gamma}^{p k} h^{k}-\dot{\Gamma}^{k p} h^{p}+S_{h}{ }^{k}
\end{aligned}
$$

Where superscript " $k$ " denotes the k-th phase (which could be liquid $(l)$ or vapour $(v)$ ), $\rho^{k}$ is the density, $\dot{\Gamma}^{k}$ is the mass transfer rate between phases, $P$ is pressure, $\vec{u}^{k}$ is the velocity vector and $\alpha^{k}$ is the volume fraction of the $\mathrm{k}$-th phase. Additionally, $g$ is the gravitational acceleration vector and $S_{u}{ }^{k}$ is the inter-phase momentum transfer term, $S_{h}{ }^{k}$ is the inter-phase energy transfer term, $h^{k}$ is the enthalpy, $q^{k}$ is the heat flux, $t$ is the time, $\tau$ is the shear stress and $Q^{\text {exchange,pk }}$ is the direct heat transfer to phase " $k$ " from the other phases and can be calculated as:

$$
Q^{\text {exchange, } p k}=h_{\text {interfacial }} A_{\text {interfacial }}\left(T_{p}-T_{k}\right)
$$

Where $T, h_{\text {interfacial }}$ and $A_{\text {interfacial }}$ are the fluid temperature, interface heat transfer coefficient (see Eq. 23) and interfacial area concentration respectively. The interfacial area concentration is a very important parameter for calculating the interfacial mass, momentum and energy transfer rates. (See Eq. 14).

We use the well-known realisable $k$ - $\varepsilon$ method to model liquid- and gas- phase turbulence as its suitable performance for the simulation of the pool boiling has been approved previously approved [27-28]. The mathematical formulation for the method $k-\varepsilon$ is presented by $[35,36]$ :

$$
\frac{\partial\left(\alpha^{k} \rho^{k} k^{k}\right)}{\partial t}+\nabla \cdot\left(\alpha^{k} \rho^{k} k^{k} \vec{u}^{k}\right)=\nabla \cdot\left(\alpha^{k} \frac{\mu_{T}^{k}}{\sigma_{k}} \nabla k^{k}\right)+\alpha^{k} \tau_{T}^{k}: \nabla \vec{u}^{k}-\alpha^{k} \rho^{k} \varepsilon^{k}+S_{k^{k}}^{i n t}
$$




$$
\begin{aligned}
& \frac{\partial\left(\alpha^{k} \rho^{k} \varepsilon^{k}\right)}{\partial t}+\nabla \cdot\left(\alpha^{k} \rho^{k} \varepsilon^{k} \vec{u}^{k}\right)=\nabla \cdot\left(\alpha^{k} \frac{\mu_{T}^{k}}{\sigma_{\varepsilon}} \nabla \varepsilon^{k}\right)+\alpha^{k} \frac{\varepsilon^{k}}{k^{k}}\left(C_{\varepsilon 1} \tau_{T}^{k}: \nabla \vec{u}^{k}-C_{\varepsilon 2} \rho^{k} \varepsilon^{k}\right)+S_{\varepsilon^{k}}^{i n t} \\
& \tau_{T}^{k}=\mu_{T}^{k}\left[\nabla \vec{u}^{k}+\left(\nabla \vec{u}^{k}\right)^{t}-\frac{2}{3}\left(\nabla \cdot \vec{u}^{k}\right) I\right]-\frac{2}{3} \rho^{k} k^{k} I
\end{aligned}
$$

In Eqs. 5 and 6, $k$ and $\varepsilon$ denote the turbulence kinetic energy and dissipation rate, respectively. The constants in Eqs. 5 and 6 are, as in Speziale [37] and Gatski and Speziale [38], set to the followings:

$$
C_{\mu}=0.09, \quad \sigma_{k}=1.0, \quad \sigma_{\varepsilon}=1.3, \quad C_{\varepsilon 1}=1.44, \quad C_{\varepsilon 2}=1.92
$$

Ultimately, the interaction of nucleated bubbles with the turbulent fluid flow of the liquid is accounted for by using two source terms of $S_{k^{\prime}}^{\text {int }}$ and $S_{\varepsilon^{\prime}}^{\text {int }}$, which are expressed by the following equations [39]:

$$
\begin{aligned}
& S_{k^{l}}^{\text {int }}=-\left(F^{l, d r a g}+F^{l, v m}\right) \cdot\left(\vec{u}^{v}-\vec{u}^{l}\right) \\
& S_{\varepsilon^{l}}^{\text {int }}=C_{\varepsilon 3} \frac{S_{k^{t}}^{\text {int }}}{\tau_{b}}, \quad \tau_{b}=\left(\frac{\left(d^{v}\right)^{2}}{\varepsilon^{l}}\right)^{1 / 3}
\end{aligned}
$$

The inter-phase momentum transfer term $\left(S^{k}\right)$ at the liquid-gas interface accounts for the forces due to viscose $\operatorname{drag}\left(F^{k, \text { Drag }}\right)$, lateral lift $\left(F^{k, l i f}\right)$, virtual mass $\left(F^{k, v m}\right)$, turbulent dispersion $\left(F^{k, \text { Dispersion }}\right)$ and wall lubrication force $\left(F^{k, w a l l}\right)$ [39]:

$$
S^{k}=F^{k, \text { drag }}+F^{k, l i j t}+F^{k, v m}+F^{k, \text { dispersion }}+F^{k, \text { wall }}
$$


Table 1. Formulation of interfacial forces for continuous phase of " $k$ " and the dispersed phase of "l".

\begin{tabular}{|c|c|}
\hline Reference & Formulation \\
\hline Clift et al. [40] & 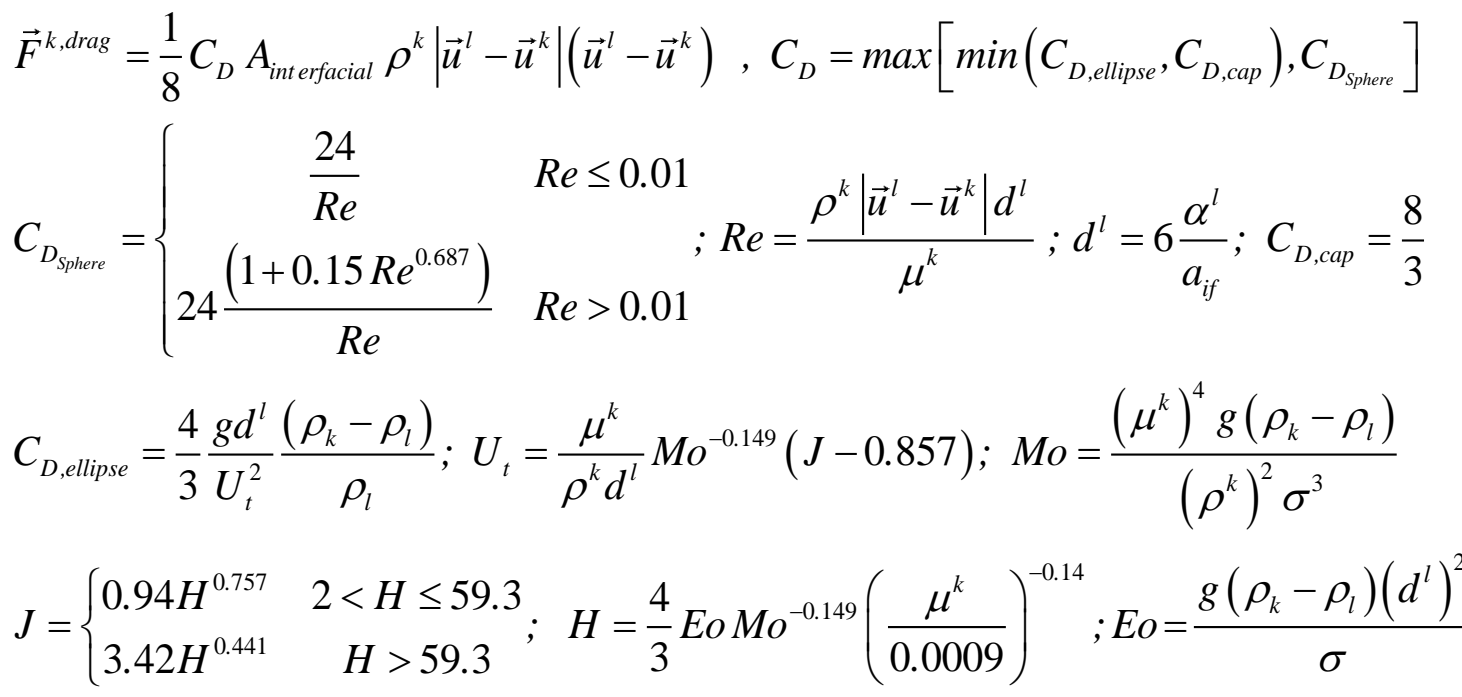 \\
\hline Tomiyama [41] & $\begin{array}{l}\vec{F}^{k, l i f t}=-\vec{F}^{l, l i f t}=C_{L} \alpha^{l} \rho^{k}\left(\vec{u}^{l}-\vec{u}^{k}\right) \times\left(\nabla \times \vec{u}^{k}\right) \\
\min \left[0.288 \tanh (0.121 \operatorname{Re}), f\left(E o_{d}\right)\right] \\
C_{L}=\left\{\begin{array}{cc}f\left(E o_{d}\right)=0.00105 E o_{d}{ }^{3}-0.0159 E o_{d}{ }^{2}-0.0204 E o_{d}+0.474 & 4<E o<10 \\
-0.29 & E o>10\end{array}\right. \\
E o_{d}=\frac{g\left(\rho^{k}-\rho^{l}\right)\left(d^{l}\right)^{2}}{\sigma}\left(1+0.163 E o^{0.757}\right)^{2 / 3} ; E o=\frac{g\left(\rho^{k}-\rho^{l}\right)\left(d^{l}\right)^{2}}{\sigma}\end{array}$ \\
\hline Antal et al. [42] & $\vec{F}^{k, v m}=-\vec{F}^{l, v m}=0.5 \alpha^{l} \rho^{k}\left(\frac{D \vec{u}^{l}}{D t}-\frac{D \vec{u}^{k}}{D t}\right)$ \\
\hline Burns et al. [43] & $\begin{array}{l}\vec{F}^{k, \text { wall }}=C_{w} \alpha^{l} \rho^{k}\left|\vec{u}^{l}-\vec{u}^{k}\right|^{2} n_{w} \\
C_{w}=\max \left(0, \frac{C_{w 1}}{d^{l}}+\frac{C_{w 2}}{y_{w}}\right) ; C_{w 1}=-0.01 ; C_{w 2}=0.05\end{array}$ \\
\hline --- & $\vec{F}^{k, \text { dispersion }}=-\vec{F}^{l, \text { dispersion }}=C_{D} \frac{\mu_{T}^{l}}{\rho^{l} S c_{b}}\left(\frac{\nabla \alpha^{l}}{\alpha^{l}}-\frac{\nabla \alpha^{k}}{\alpha^{k}}\right)$ \\
\hline
\end{tabular}

A detailed formulation of all the interfacial forces is presented in Table 1. 


\subsection{RPI boiling model}

To model boiling along the tube wall, the RPI nucleate boiling model of Kurul and Podowski [44] is employed. In the RPI model, the total wall heat flux is decomposed into three distinctive elements:

$\dot{q}_{w}=\dot{q}_{C}+\dot{q}_{Q}+\dot{q}_{E}$

Where $\left(\dot{q}_{C}\right)$ is the convective heat flux, $\left(\dot{q}_{Q}\right)$ is quenching heat flux and $\left(\dot{q}_{E}\right)$ is the evaporative heat flux. The convective heat flux is computed as:

$\dot{q}_{C}=h_{C}\left(T_{w}-T_{l}\right)\left(1-A_{\text {interfacial }}\right)$

In Eq. 13, $\left(h_{c}\right)$ is the single-phase heat transfer coefficient (Eq. 23), $\left(T_{w}-T_{l}\right)$ is the wall and liquid temperature difference. The interfacial area, $A_{\text {interfacial }}$, is also expressed via the Del Valle and Kenning [45] formulation as:

$A_{\text {interfacial }}=\min \left(1, K_{D K} \frac{N_{W} \pi D_{W}^{2}}{4}\right) ; \quad K_{D K}=4.8 \exp \left(-\frac{1}{80} \frac{\rho_{l} C_{p, l}\left(T_{\text {sat }}-T_{l}\right)}{\rho_{v} h_{l v}}\right)$

Where $\left(T_{s a t}\right)$ is the saturation temperature, $\left(D_{w}\right)$ is the bubble departure diameter, and $\left(N_{w}\right)$ is the nucleation site density. The nucleation site density is determined by the correlation of Lemmert and Chawla [23]: 
$N_{w}=C^{n}\left(T_{w}-T_{\text {sat }}\right)^{n} ; C=210, n=1.805$

The bubble departure diameter in the RPI model is expressed by [24]:

$$
\begin{aligned}
& D_{w}=2.421 \times 10^{-5} p^{0.709}\left(\frac{a}{b \sqrt{\varphi}}\right) \\
& a=\frac{T_{\text {wall }}-T_{\text {sat }}}{2 \rho_{v} h_{l v}} \sqrt{\frac{\rho_{l} C_{p, l} k_{l}}{\pi}} \\
& b= \begin{cases}\frac{T_{\text {sat }}-T_{l}}{2\left(1-\frac{\rho_{l}}{\rho_{v}}\right)} e^{\left(\frac{T_{s a t}-T_{l}}{3}-1\right)} & \left(T_{\text {sat }}-T_{l}\right) \leq 3 \\
\frac{T_{\text {sat }}-T_{l}}{2\left(1-\frac{\rho_{l}}{\rho_{v}}\right)} & \left(T_{\text {sat }}-T_{l}\right)>3\end{cases} \\
& \varphi=\max \left(\left(\frac{U_{\text {near wall }}}{0.61}\right)^{0.47}, 1.0\right)
\end{aligned}
$$

As vapour bubbles periodically detach from the solid wall, a liquid film fills the wall neighbourhood. The average time of the heat transfer rate for this substitute liquid film is expressed by:

$$
\dot{q}_{Q}=\frac{k_{l}}{\sqrt{\pi \frac{k_{l}}{\rho_{l} C_{p, l}} \tau}}\left(T_{w}-T_{l}\right)
$$

Where $\left(k_{l}\right)$ is the liquid thermal conductivity and $(\tau)$ is the period of the bubble detachment process and can be calculated as [25]: 


$$
\frac{1}{\tau}=\sqrt{\frac{4 g\left(\rho_{l}-\rho_{v}\right)}{3 \rho_{l} D_{w}}}
$$

Evaporative heat flux is also represented by:

$$
\dot{q}_{E}=\frac{\pi}{6} D_{w}^{3} N_{w} \rho_{v} h_{l v}
$$

Where $h_{l v}$ is the latent heat of evaporation.

The mass transfer rate between liquid and vapour phases occurs in two distinct regions, near the hot wall and in the bulk liquid. The mass transfer near the hot wall can be calculated by:

$$
\dot{\Gamma}^{l v, 1}=\frac{\dot{q}_{E}}{h_{l v}+c_{p, l}\left(T_{s a t}-T_{l}\right)}
$$

The mass transfer rate at the bulk saturated liquid region can be determined as:

$$
\begin{aligned}
& \dot{\Gamma}^{l v, 2}=\frac{\dot{q}_{l}+\dot{q}_{v}}{h_{l v}} \\
& \dot{q}_{l}=\frac{k_{l} N u_{l}}{D_{w}}\left(T_{s a t}-T_{l}\right) ; \dot{q}_{v}=\frac{\alpha_{v} \rho_{v} c_{p, v}}{\delta t}\left(T_{s a t}-T_{v}\right)
\end{aligned}
$$


Where $\delta t$ denotes the time scale set to 0.05 [27-28]. The correlation of Ranz and Marshall [46] is used for computing the $N u_{l}$ at the interface as:

$$
N u_{l}=2+0.6 \operatorname{Re}_{l}^{1 / 2} \operatorname{Pr}_{l}^{1 / 3}
$$

Where $\operatorname{Re}_{l}$ and $\operatorname{Pr}_{l}$ are the liquid Reynolds and Prandtl numbers respectively.

Finally, the boiling heat transfer coefficient, $h_{b}$, is calculated through the following equation [16]:

$$
h_{b}=\frac{q_{T}^{\prime \prime}}{T_{\text {wall,ave }}-T_{\text {sat }}}
$$

Where $q^{\prime \prime}{ }_{T}$ and $T_{\text {wall, }}$ ave are the top tube surface heat flux and average temperature, respectively. As the main purpose of the present study is to investigate the bundle effect on the boiling heat transfer coefficient, all the presented boiling heat transfer coefficients are for the top tube. Therefore, we mean heat transfer coefficient for the top tube whenever the statement "boiling heat transfer coefficient" is used in the subsequent sections.

\subsection{Solution method and assumptions}

The numerical simulation of pool boiling on smooth, inclined tubes was performed on an ANSYS Fluent 17.1 commercial CFD package. A phase-coupled SIMPLE method was employed to handle the pressure-velocity coupling. The convective terms in the governing equations were approximated by a second-order upwind scheme and the gradient of all flow variables was calculated using the least-square cell-based method. To solve the vapour volume fraction equation 
in a two phase flow solver, upwind schemes are generally unsuitable for interface tracking because of their overly diffusive nature which results in unphysical thickening of the fluid interfaces. Down-wind differencing schemes, while generally able to retain the sharpness of the interface, are unbounded and often give unphysical oscillatory results. To benefit from the stability of upwind differencing and the accuracy of down-winding for interface tracking, a modified version of the HRIC scheme is used for the current simulations. The modified HRIC scheme consists of a nonlinear blend of upwind and downwind differencing [47].

Transient simulations were performed at each time step via a global courant number of 0.1 , which guarantees the stability of the numerical approach. The simulation process continued until the convergence criterion of $10^{-5}$ for all the flow equations. The corresponding simulation time to obtain this criterion was $t=60 \mathrm{~s}$.

The following assumptions are considered for the present numerical simulation:

1. The current problem is transient and turbulent.

2. The properties of each phase are assumed to be constant under the specified operating condition.

3. The contact angle between the liquid and vapour phases on the tube is considered to be $80^{\circ}, 35^{\circ}$ and $15^{\circ}$ for water, ethanol and FC-72, respectively [48]. The contact angles are used to consider the effect of surface roughness $[49,50]$. In the present study the tube surface roughness is set at $0.1 \mu \mathrm{m}[16]$. 
4. A time step size of $10^{-5} \mathrm{~s}$ is chosen for the simulation. Moreover the iterations count per time step was set to 100 to assure that the solution is fairly converged at each time step. This value was achieved through a try and error procedure.

Furthermore the following boundary conditions are considered for the simulations:

1. The walls of the pool are considered to be adiabatic.

2. No-slip condition and constant heat flux are set on the tube walls.

3. The upper side of the pool is considered to be open (pressure inlet) to attain the saturation condition corresponding to the working fluid.

\subsection{Validation of the present numerical method}

To validate the numerical approach and further investigate pool boiling heat transfer on smooth tubes, the experimental setup of Kang [16] was selected as the physical setting for validation of all the numerical simulations performed in the present study. The schematic of the three-dimensional computational domain based on the experimental setup of Kang [16] is illustrated in Fig. 1(a). The whole setup is submerged into an atmospheric bath of boiling fluid with the corresponding saturation temperature of $T_{\text {sat. }}$. In addition to water (which was originally used by Kang [16] as the boiling fluid), the pool boiling behaviour of ethanol and FC-72 was explored as two other common

working fluids. FC-72 (a Fluorinert ${ }^{\mathrm{TM}}$ electrical liquid) is a stable, non-toxic, non-flammable liquid with low viscosity, which is a suitable working fluid for the heat sink of electronic devices [51]. The thermophysical properties of these three working fluids are summarised in Table 2. 


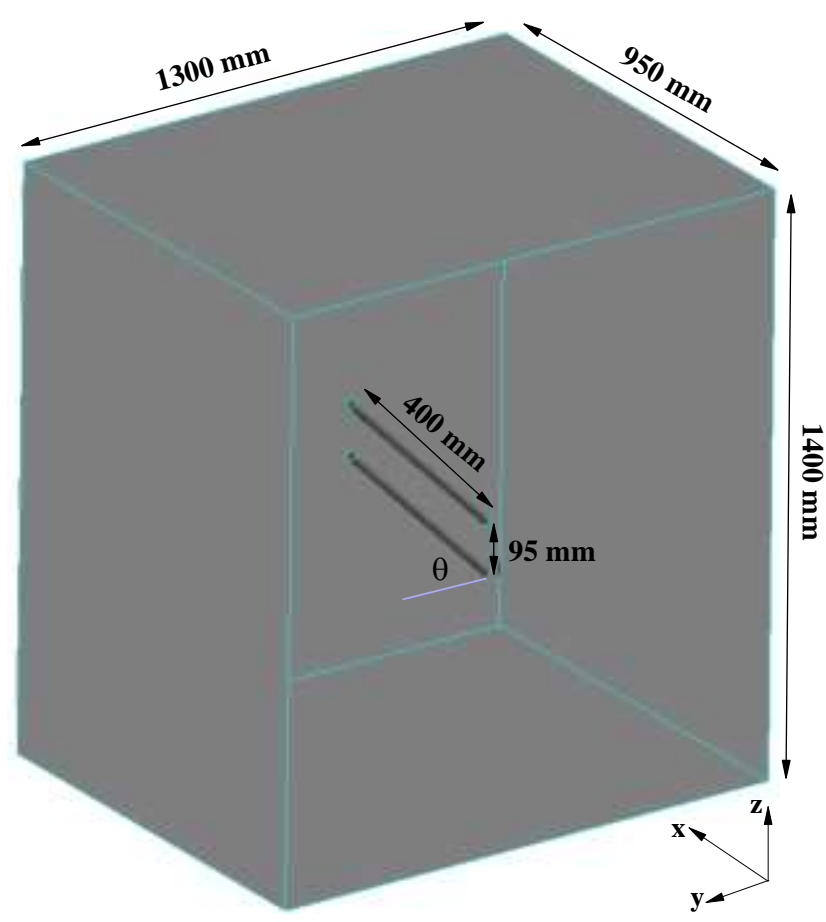

(a)
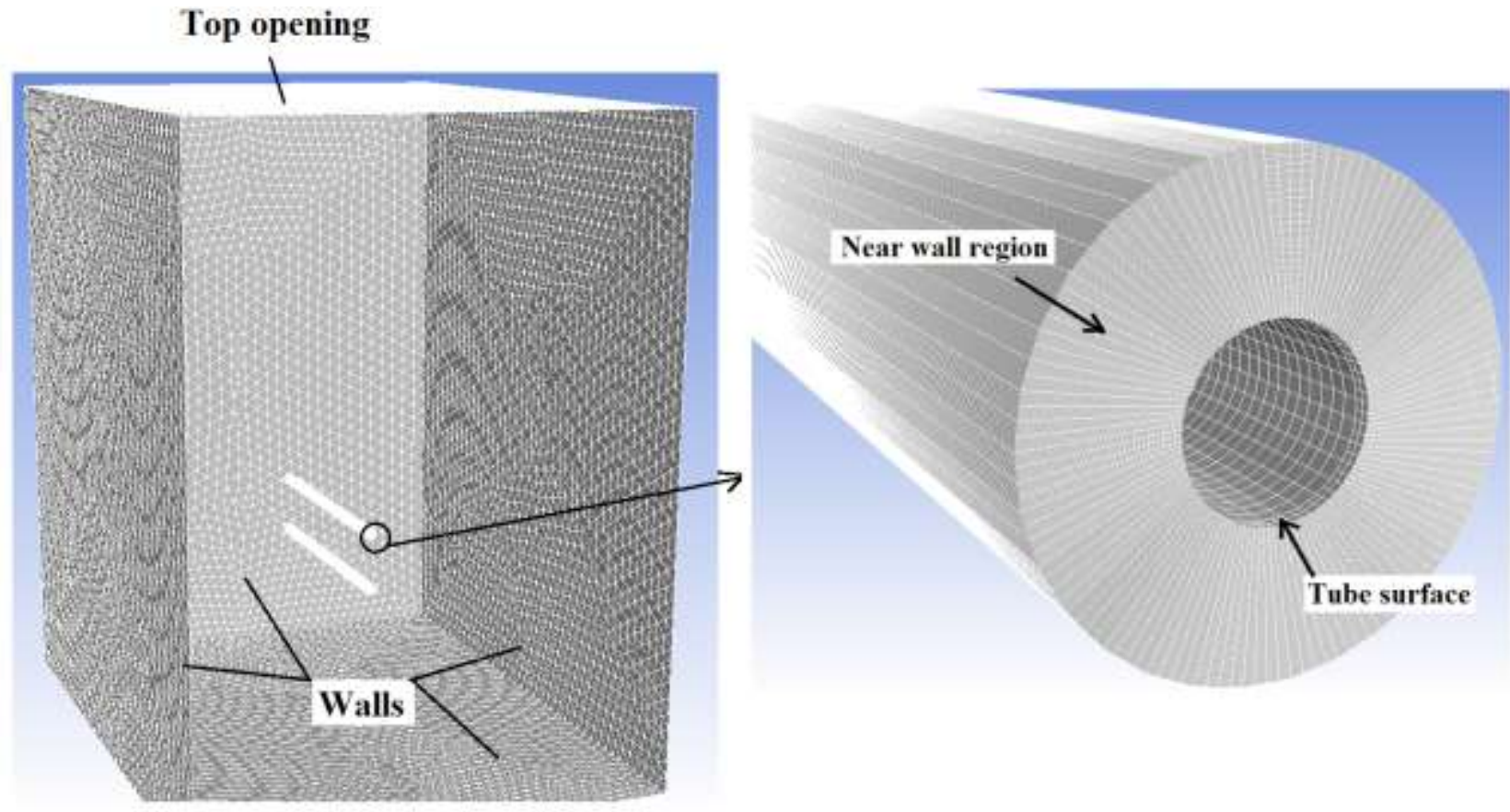

(b)

Fig. 1. (a) Schematics of the computational domain [16]; and (b) computational grid. 
Table 2. Thermophysical properties of water, ethanol and FC-72 [51].

\begin{tabular}{|c|c|c|c|}
\hline Property & Water & Ethanol & FC-72 \\
\hline Saturation temperature $\left({ }^{\circ} \mathrm{C}\right)$ & 100 & 78.3 & 56.4 \\
\hline Liquid-vapour density $\left(\mathrm{kg} / \mathrm{m}^{3}\right)$ & $959-0.597$ & $757-1.43$ & $1602-13.24$ \\
\hline Surface tension $(\mathrm{N} / \mathrm{m})$ & 0.0589 & 0.0177 & 0.0081 \\
\hline Liquid viscosity (Pa.s) & 0.00028 & 0.00044 & 0.00043 \\
\hline Liquid-specific heat $(\mathrm{J} / \mathrm{kg} . \mathrm{K})$ & 4216 & 3030 & 1052 \\
\hline Thermal conductivity (W/m.K) & 0.679 & 0.153 & 0.0572 \\
\hline Latent heat of evaporation $(\mathrm{kJ} / \mathrm{kg})$ & 2257.0794 & 962.8825 & 87.9881 \\
\hline Prandtl number & 1.74 & 8.55 & 11.82 \\
\hline
\end{tabular}

The computational grid is depicted in Fig. 1(b). As shown in this figure, two different grid types are used in this study. The regions close to the tubes are meshed with the structured quadrilateral cells. The thickness of this region is $19.5 \mathrm{~mm}$ (equal to the tube diameter). In order to capture the boundary layer effect properly, the value of $y^{+}$is set to 1-2 around the each tube. This was obtained by setting 30 boundary nodes around the tube surface. For the region far the tube surface, the pyramid cells with four nodes are used.

The effect of the mesh size on the acquired pool boiling curve for water is demonstrated in Fig. 2. The mesh size study tested thermally active $\left(q_{L}^{\prime \prime}=0\right)$ and inactive $\left(q_{L}^{\prime \prime}>0\right)$ lower tubes; four numerical meshes with different cell counts were considered. Although the numerical result for active lower tubes is more sensitive to the size of the numerical mesh, the mesh with 732921 computational cells is appropriate for this simulation, beyond which no significant change in pool 
boil curve is reported for either of the cases. Therefore, using this numerical grid for the simulations throughout the manuscript, the numerical results can be ensured.

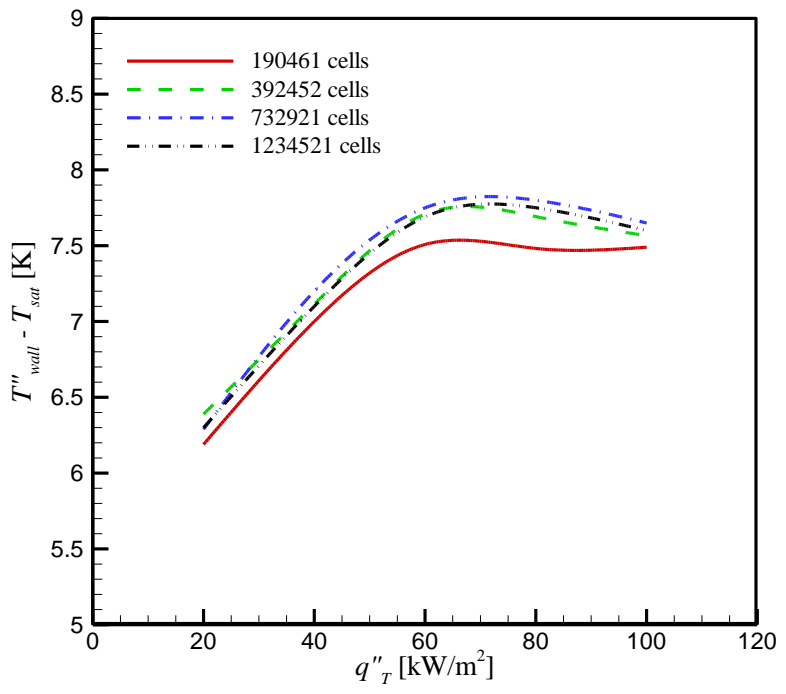

(a)

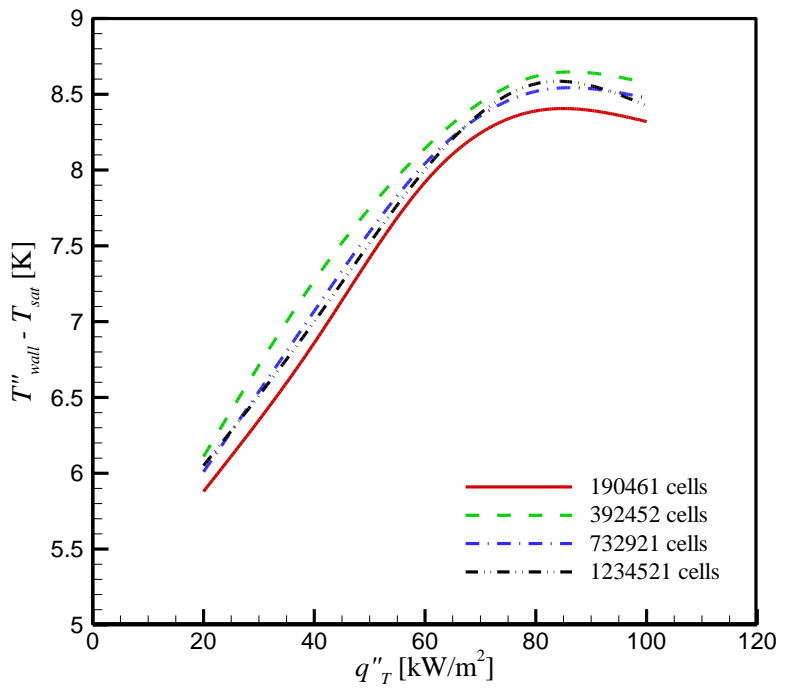

(b)

Fig. 2. Variations of wall superheat level with respect to wall heat flux for different grid sizes at $\theta=30^{\circ}$; (a)

$$
q_{L}^{\prime \prime}=0 \mathrm{~kW} / \mathrm{m}^{2} ; \text { and (b) } q_{L}^{\prime \prime}=90 \mathrm{~kW} / \mathrm{m}^{2}
$$




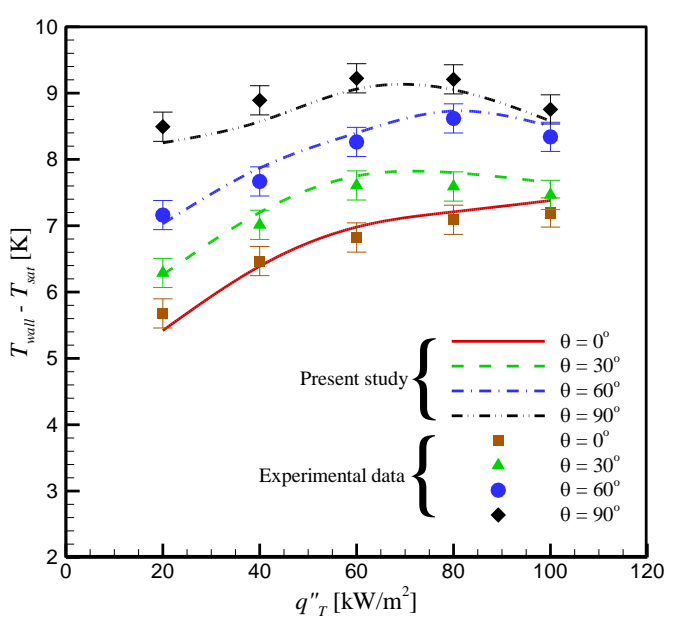

(a)

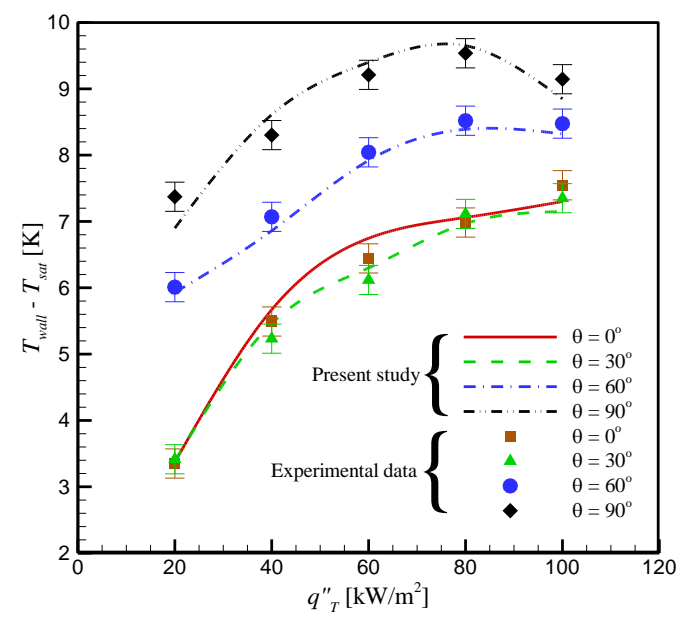

(c)

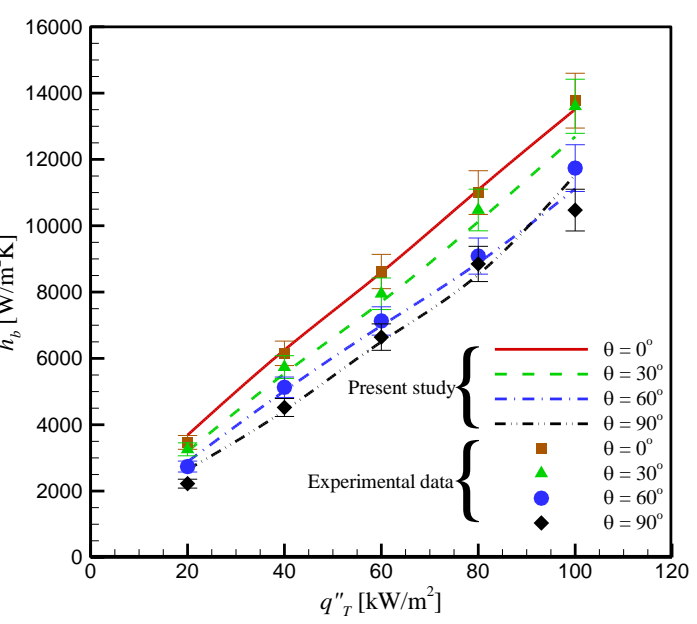

(b)

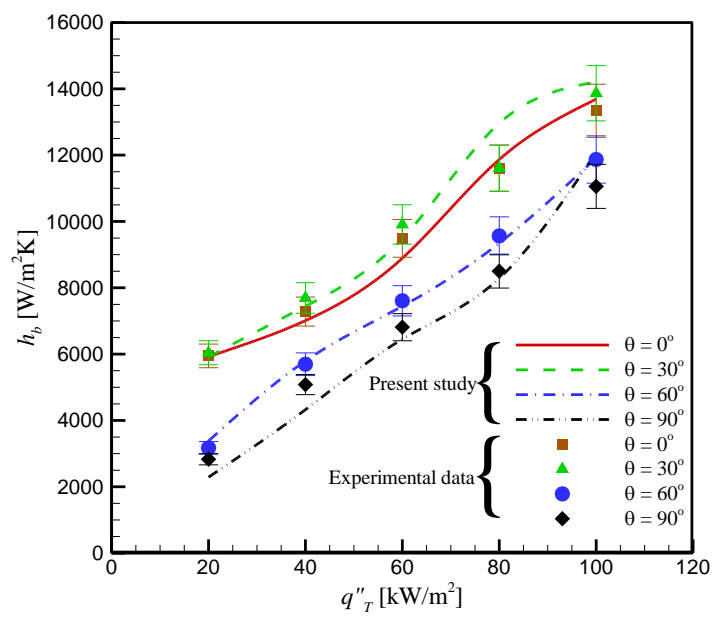

(d)

Fig. 3. Comparison of the numerical results with the experimental data of Kang [16]:

(a) Wall superheat for $q_{L}^{\prime \prime}=0 \mathrm{~kW} / \mathrm{m}^{2}$; (b) heat transfer coefficient for $q_{L}^{\prime \prime}=0 \mathrm{~kW} / \mathrm{m}^{2}$; (c) wall superheat for

$$
q_{L}^{\prime \prime}=90 \mathrm{~kW} / \mathrm{m}^{2} ; \text { and (d) heat transfer coefficient for } q_{L}^{\prime \prime}=90 \mathrm{~kW} / \mathrm{m}^{2} .
$$

A comparison between the simulated results and experimental of Kang [16] for pool boiling curves for water is given in Fig. 3 for different inclination angles and lower tube heat fluxes. As we can see, a favourable agreement is reported between the numerical results and the experimental data, which corroborates the accuracy and reliability of the numerical solution. Moreover, the overall 
heat transfer coefficient obtained from the numerical simulation coincides with the experimental measurements for various inclination angles (see Fig. 3b and Fig. 3d). The variation of the heat transfer coefficient and heat flux tends to be more irregular when the lower tube becomes thermally active.

\section{Results and Discussion}

The main purpose of this study is to perform an accurate set of numerical simulations for the pool boiling heat transfer on tube bundles and to investigate the bundle effect on the boiling heat transfer coefficient for different inclination angles and working fluids. The simulations are performed using the illustrated geometry in Fig. 1. The results presented in Fig. 3 are for water at atmospheric pressure and different inclination angle and tube surface heat fluxes. Fig. 3 shows that the boiling heat transfer coefficients, as expected, increase with increase of the heat flux of the top tube regardless of the heat flux value of the bottom tube. Another point is that as the inclination angle $(\theta)$ increases, the value of the boiling heat transfer coefficient decreases. As a result, the corresponding wall superheat value rises with $\theta$ for a given heat flux. The pool boiling curve then shifts to the right for higher inclination angles. This shift is more significant when the lower tube is active and the inclination angle is larger than $30^{\circ}$. The decline of the heat transfer coefficient with $\theta$ is attributed to a higher resistance against detachment, experienced by the vapour bubble for larger inclination angles.

Fig. 4 shows the contours of the water vapour volume fraction for $q_{L}^{\prime \prime}=0 \mathrm{~kW} / \mathrm{m}^{2}, q_{T}^{\prime \prime}=20 \mathrm{~kW} / \mathrm{m}^{2}$ and various inclination angles. In this condition the bottom tube has no effect on the top one. As $\theta$ increases, the vapour phase covers more regions around the tube surface (higher accumulation of 


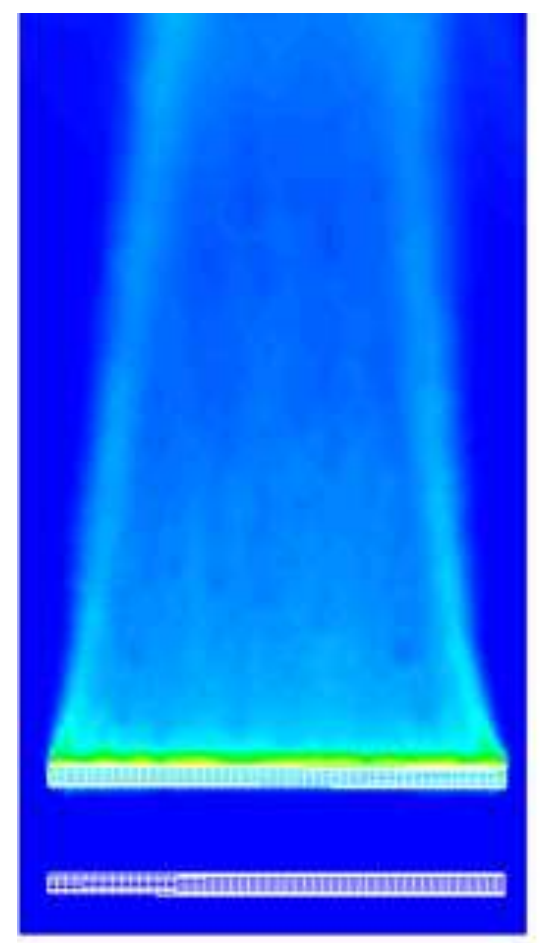

(a)

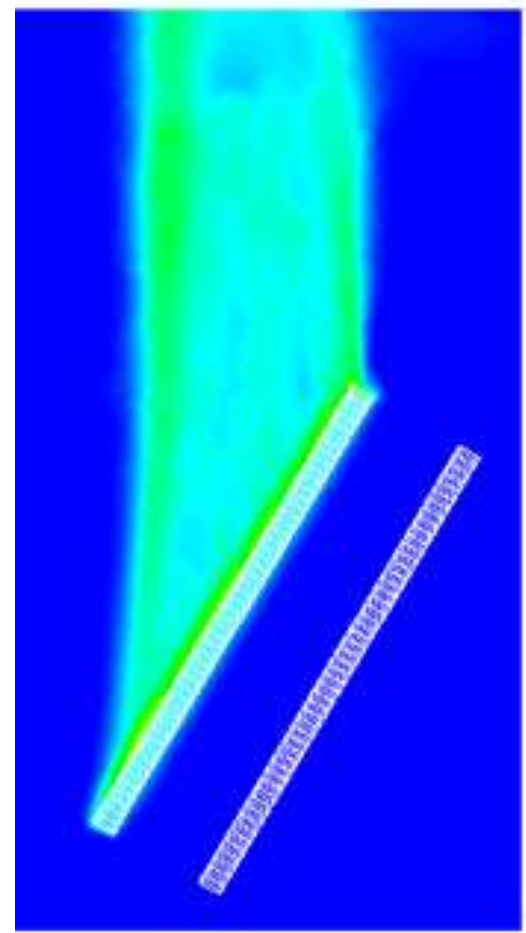

(c)

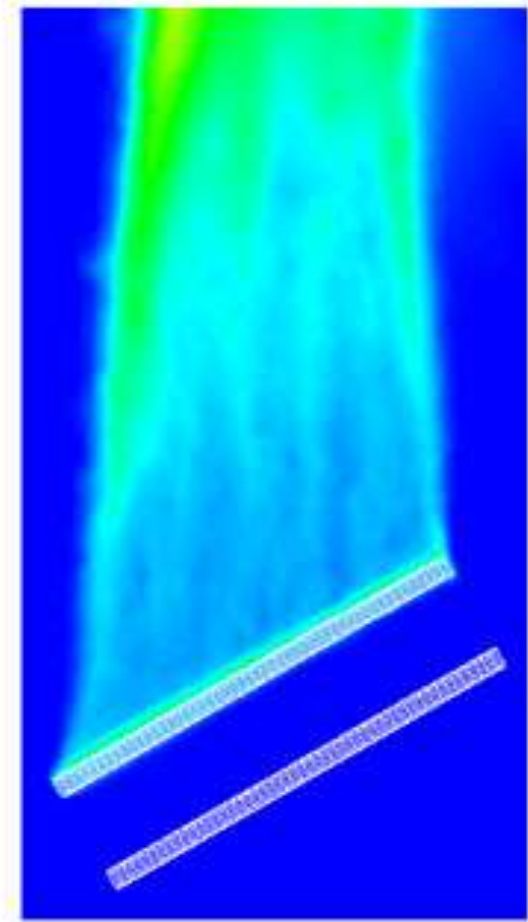

(b)

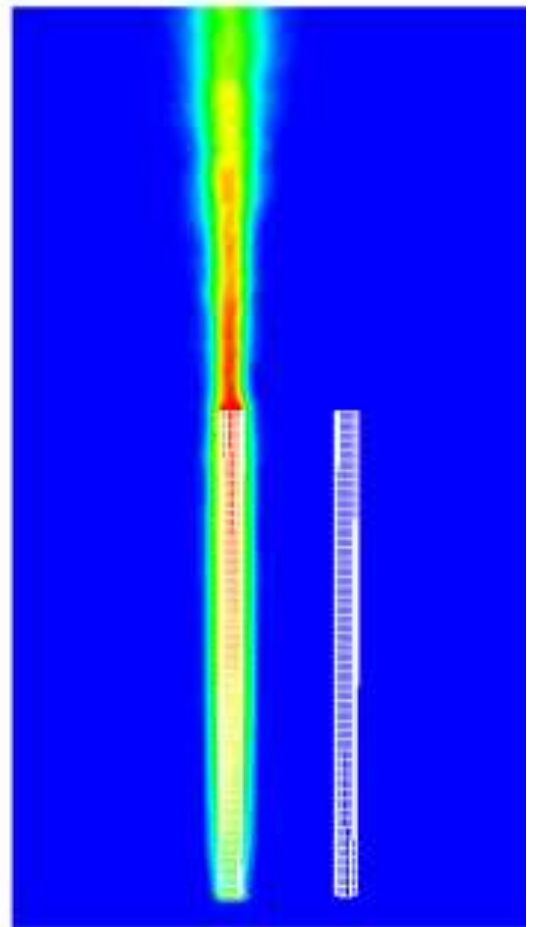

(d)

Fig. 4. Effect of inclination angle on vapour volume fraction for water at $q_{L}^{\prime \prime}=0 \mathrm{~kW} / \mathrm{m}^{2}$ and $q_{T}^{\prime \prime}=20 \mathrm{~kW} / \mathrm{m}^{2}$ : (a) $\theta$ $=0^{\circ}$; (b) $\theta=30^{\circ}$; (c) $\theta=60^{\circ}$; and (d) $\theta=90^{\circ}$ (contour levels: 0.0 to 0.02 ). 
vapour phase and vapour volume fraction) and prevents the cold liquid from reaching the tube surface which consequently leads to increase in temperature difference between the tube surface and the saturation temperature. This would also cause a decrease in transfer coefficient.

This detailed numerical simulation enables researchers to investigate the vapour phase formation and its temporal evolution during pool boiling on heated surfaces. Contours of the water vapour volume fraction for the condition of $q_{L}^{\prime \prime}=0 \mathrm{~kW} / \mathrm{m}^{2}, q_{T}^{\prime \prime}=20 \mathrm{~kW} / \mathrm{m}^{2}$ are illustrated in Fig. $5(\theta=$ $\left.30^{\circ}\right)$ and Fig. $6\left(\theta=60^{\circ}\right)$, for six time steps. At earlier times, vapour bubbles are nucleated on the heated tube surfaces and their formation rate is proportional to the heat flux of the tube (i.e., the vapour volume fraction is higher on the tube with a larger heat flux). As time progresses, the nucleated vapour bubbles coalesce and detach from the tube surface, rising through the vertical column of the boiling liquid due to buoyancy forces. As a result, non-zero levels of fractionalvolume vapour phase spread towards the regions far from the tube surface. The coalescence and detachment of the nucleated bubbles can be distinguished by the change of vapour volume fraction, due to utilization of Eulerian-Eulerian approach in which a fog of vapour phase, vapour volume fraction, can be seen rather than separate and distinct bubbles. As steady state is reached, a continuous region above the heated tube is recognised as the position with high levels of vapour volume fraction; this can be described as the vapour phase preferred rising path. A comparison between Figs. 5 and 6 reveals that as the inclination angle of the tubes increases, the vapour volume fraction at the tube surface increases, as well. As mentioned earlier, this can be justified by the increase in resistance against the bubble detachment as the inclination angle elevates. This results in the formation of larger vapour bubbles on the heated surfaces. The larger bubbles slide along the tube surface and detach near the upper end of the tube (see the large volume fraction in the 
vicinity of the upper ends of the tubes). Additionally, for larger inclination angles, a smaller length of upper tube is affected by the vapour bubbles detached from the lower tube, which degrades the heat transfer-enhancing effect of a thermally active lower tube.

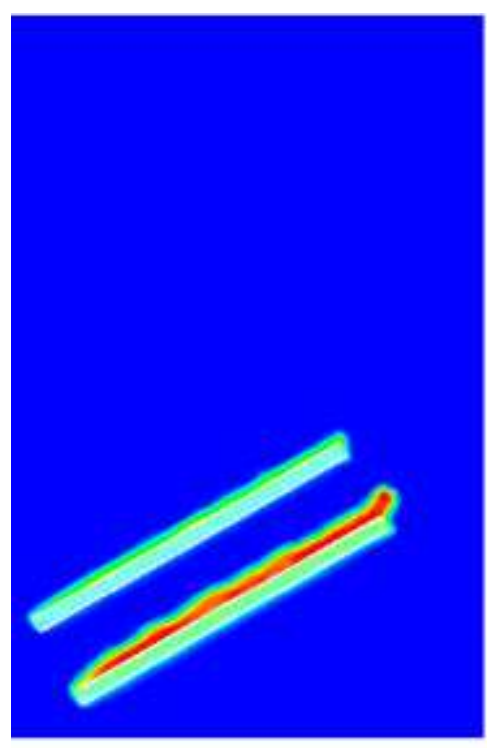

(a)

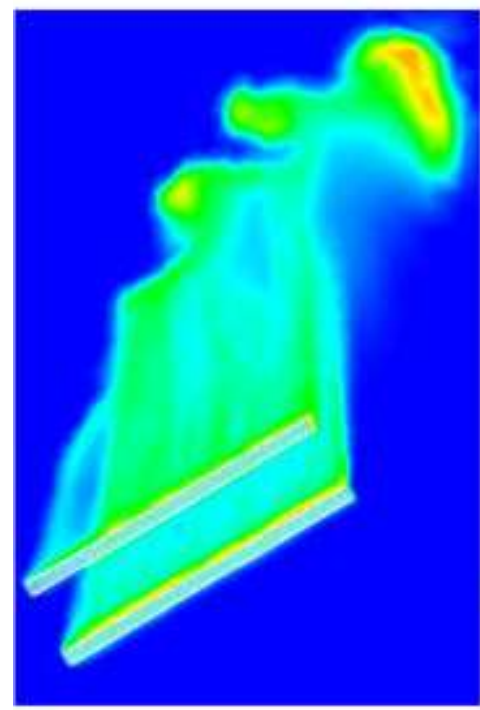

(d)

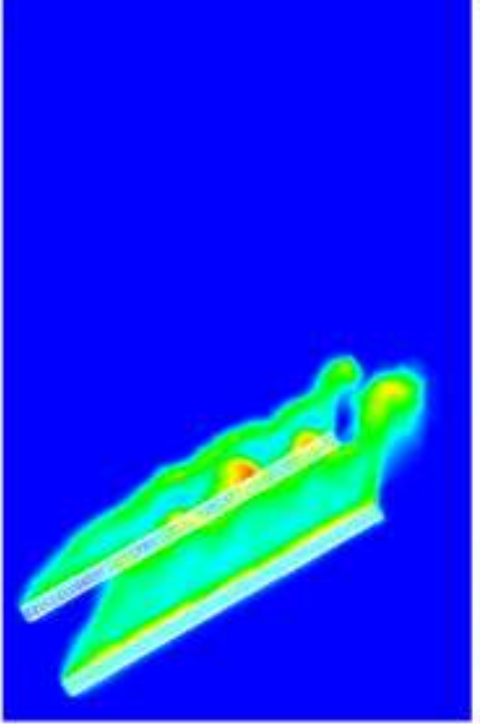

(b)

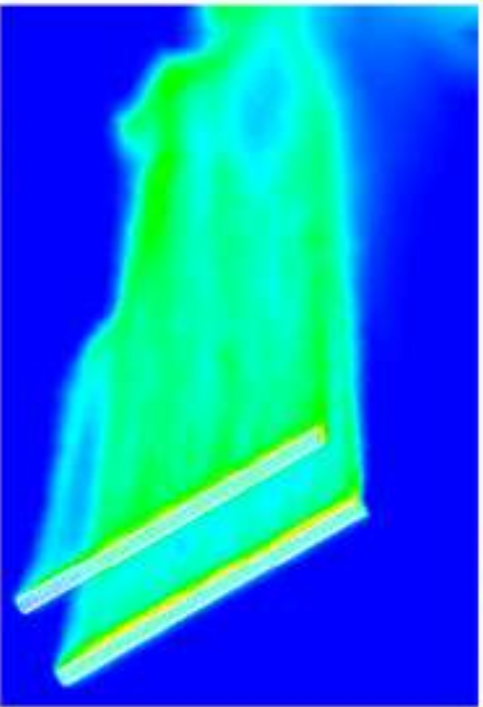

(e)

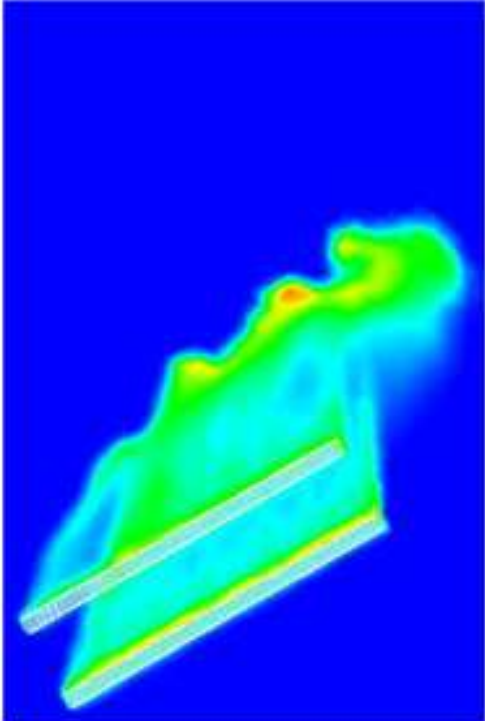

(c)

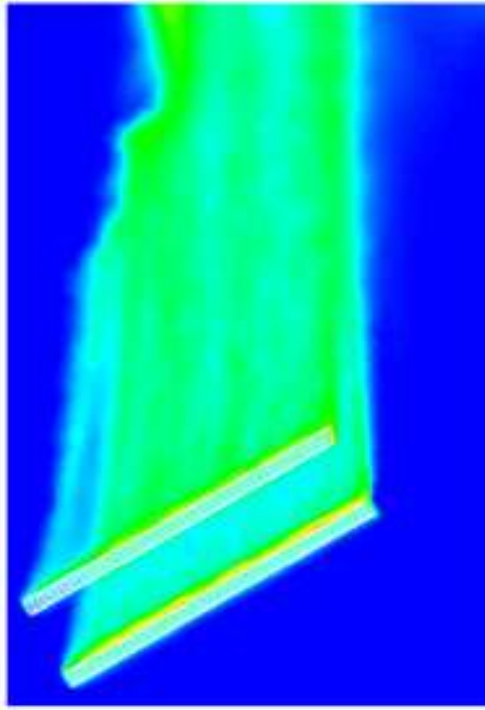

(f)

Fig. 5. Temporal evolution vapour phase volume fraction for water at $q_{T}^{\prime \prime}=40 \mathrm{~kW} / \mathrm{m}^{2}, q_{L}^{\prime \prime}=90 \mathrm{~kW} / \mathrm{m}^{2}$ and $\theta=$

$$
30^{\circ}: \text { (a) } t=2 \mathrm{~s} \text {; (b) } t=4 \mathrm{~s} \text {; (c) } t=6 \mathrm{~s} \text {; (d) } t=8 \mathrm{~s} \text {; (e) } t=10 \mathrm{~s} \text {; and }
$$

(f) $t=12 \mathrm{~s}$ (contour levels: 0.0 to 0.025$)$. 


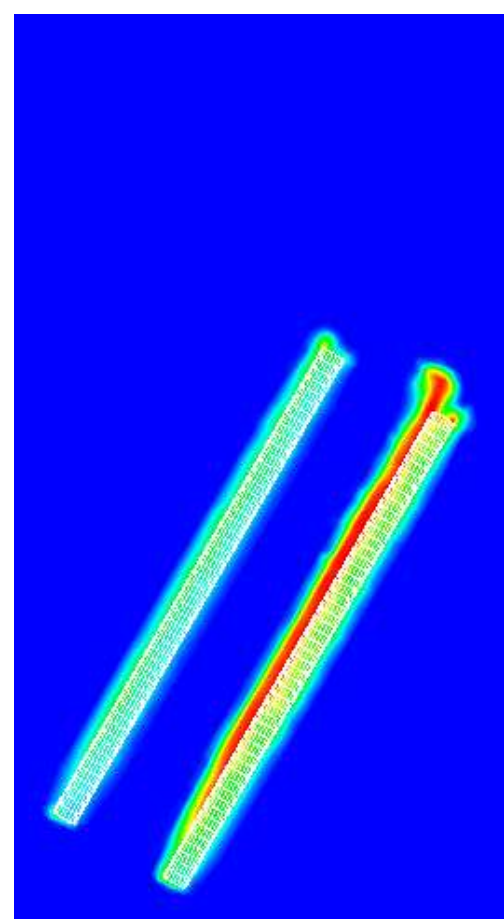

(a)

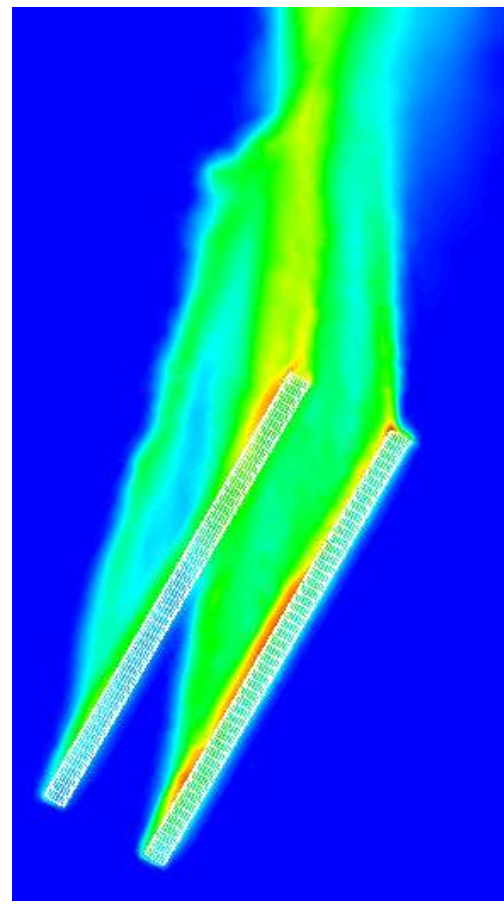

(d)

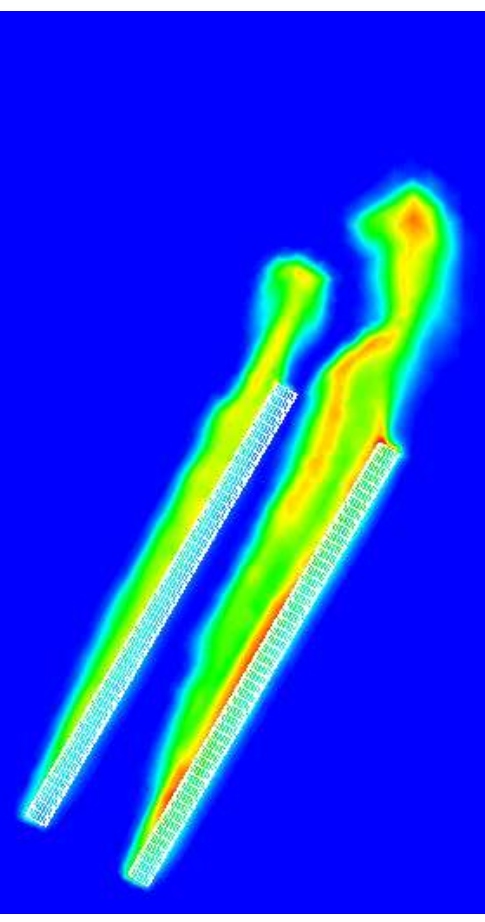

(b)

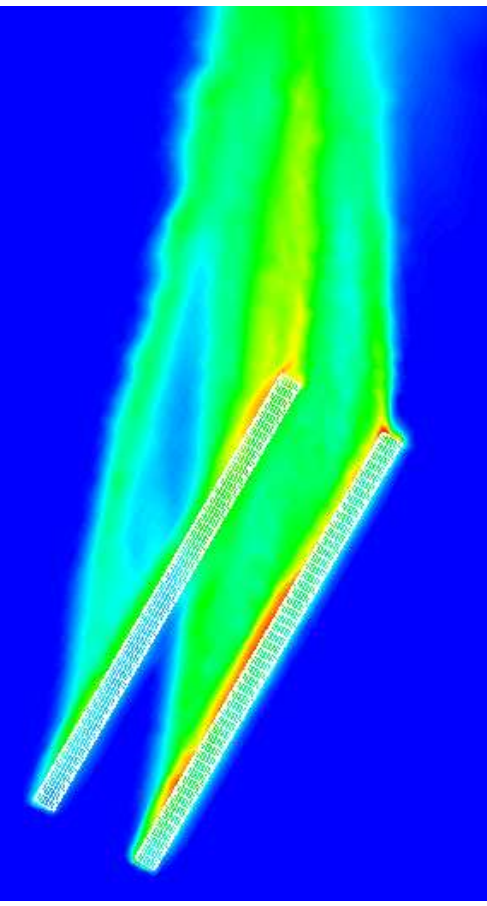

(e)

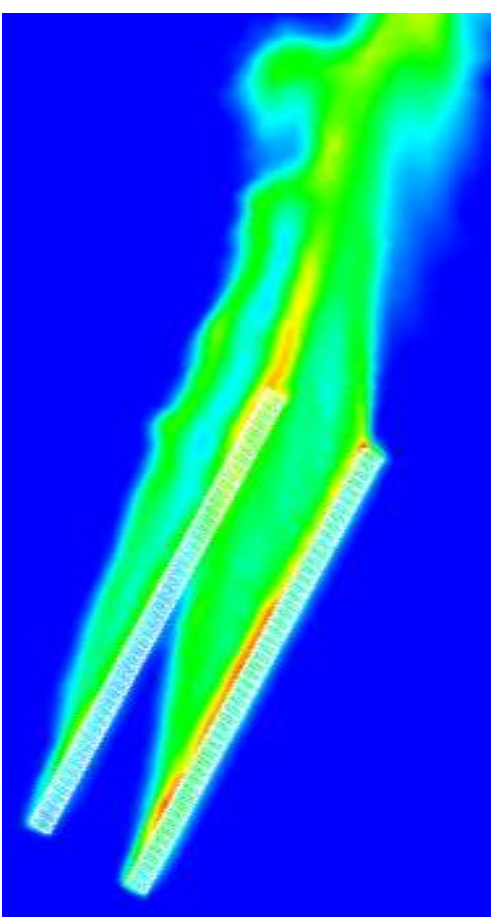

(c)

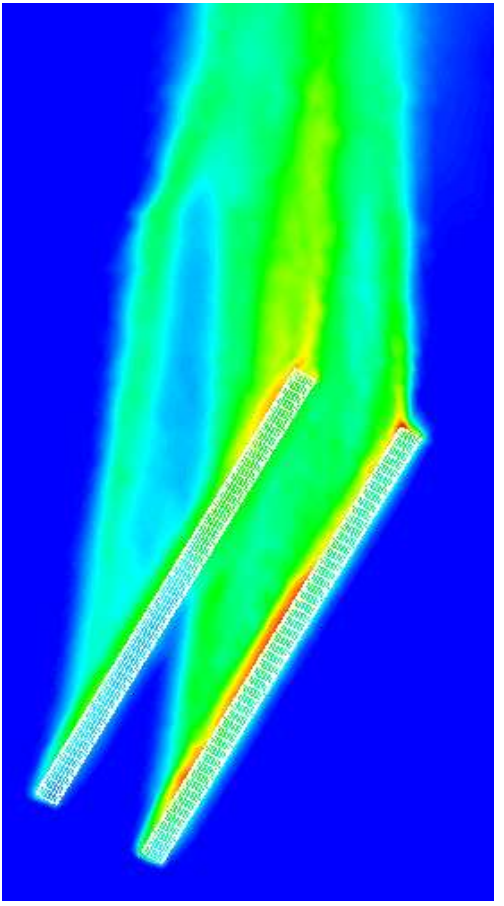

(f)

Fig. 6. Evolution of vapour phase during time for water at $q_{T}^{\prime \prime}=40 \mathrm{~kW} / \mathrm{m}^{2}, q_{L}^{\prime \prime}=90 \mathrm{~kW} / \mathrm{m}^{2}$ and $\theta=60^{\circ}$ : (a) $t=2$ $\mathrm{s}$; (b) $t=4 \mathrm{~s}$; (c) $t=6 \mathrm{~s}$; (d) $t=8 \mathrm{~s}$; (e) $t=10 \mathrm{~s}$; and (f) $t=12 \mathrm{~s}$ (contour levels: 0.0 to 0.025 ). 
The effect of the thermophysical properties of the boiling fluid on the pool boiling curve and pool boiling heat transfer coefficient is depicted in Figs. 7 to 10 for inclination angles of $0^{\circ}, 30^{\circ}, 60^{\circ}$ and $90^{\circ}$, respectively, with thermally active/inactive lower tubes.

In Figs. 7 and 8, the wall superheat level and boiling heat transfer coefficient for different working fluids, $q_{T}^{\prime \prime}$ and inclination angles at $q_{L}^{\prime \prime}=0 \mathrm{~kW} / \mathrm{m}^{2}$ are shown, respectively. The highest heat transfer coefficient, and subsequently the lowest wall superheat, is reported for water because of its superior thermal conductivity and specific heat together with its low viscosity. Another factor that influences the increase of the pool boiling heat transfer for water is its relatively high contact angle, which increases the number of active nucleation sites on the solid surface and promotes the nucleation process and bubble detachment. The second-highest heat transfer coefficients are obtained for ethanol, and the lowest are reported for FC-72. Moreover, for all the boiling fluids, the heat transfer coefficient increases with heat flux. The largest rate of increase in the heat transfer coefficient belongs to FC-72, which leads to the steepest pool boiling curve for this boiling fluid. The effect of the inclination angle and lower tube heat flux is the same for all the boiling fluids considered, and any increases in inclination angle decrease the heat transfer coefficient. When the lower tube become thermally active, vapour bubbles detach from the lower tube, arrive at the upper tube and increase the turbulence and phase velocities near this tube; which increases the heat transfer rate and heat transfer coefficient per the condition where the lower tube is thermally inactive. The effect is more pronounced for water at low inclination angles. 


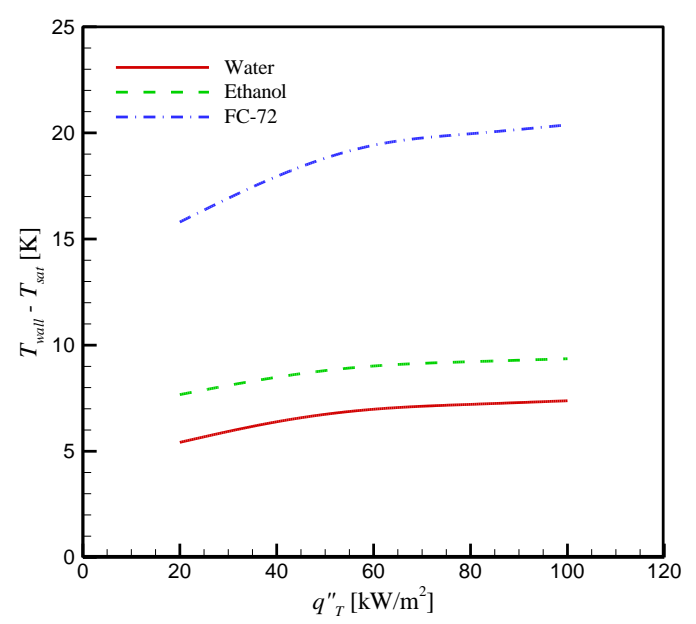

(a)

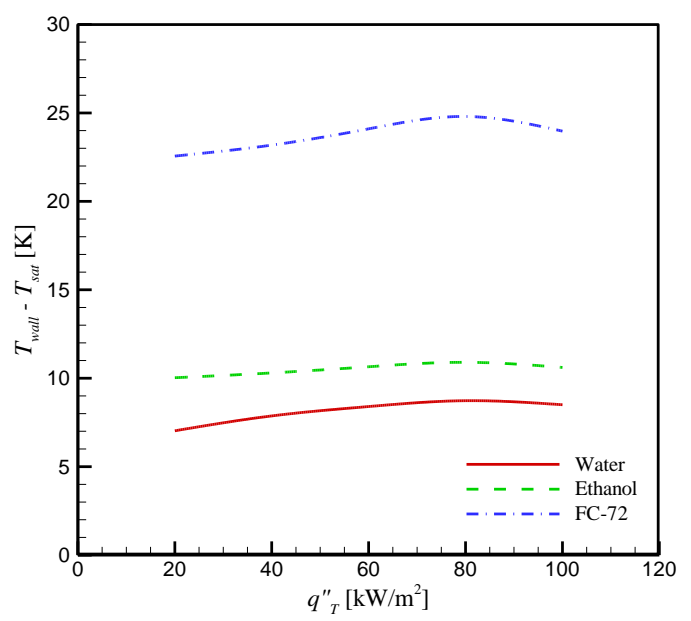

(c)

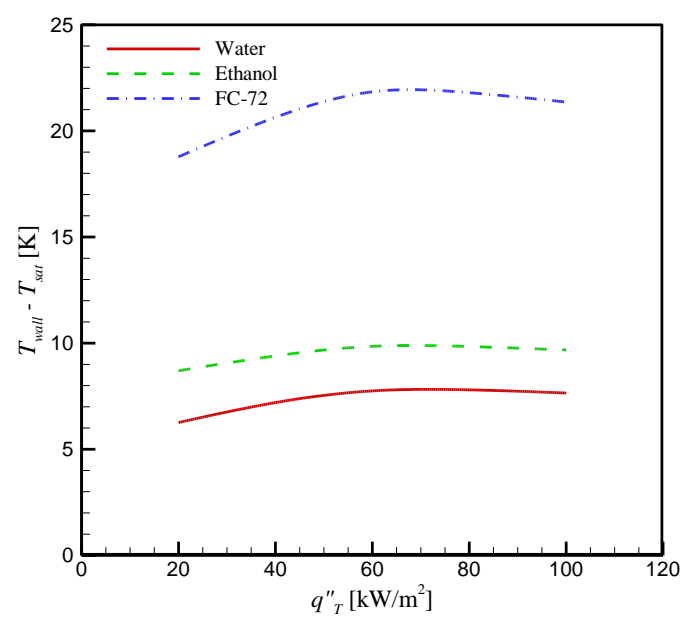

(b)

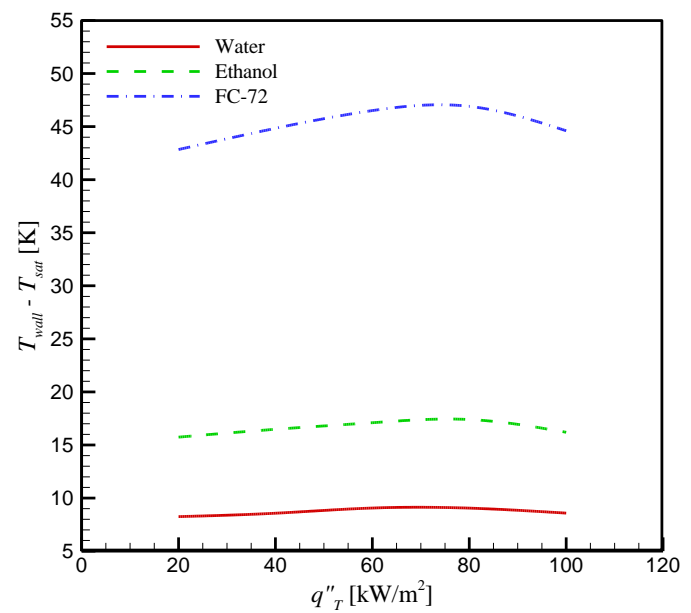

(d)

Fig. 7. Comparison between the variations of the wall superheat level with wall heat flux for different working fluids at $q_{L}^{\prime \prime}=0 \mathrm{~kW} / \mathrm{m}^{2}$ : (a) $\theta=0^{\circ}$; (b) $\theta=30^{\circ}$; (c) $\theta=60^{\circ}$; and (d) $\theta=90^{\circ}$. 


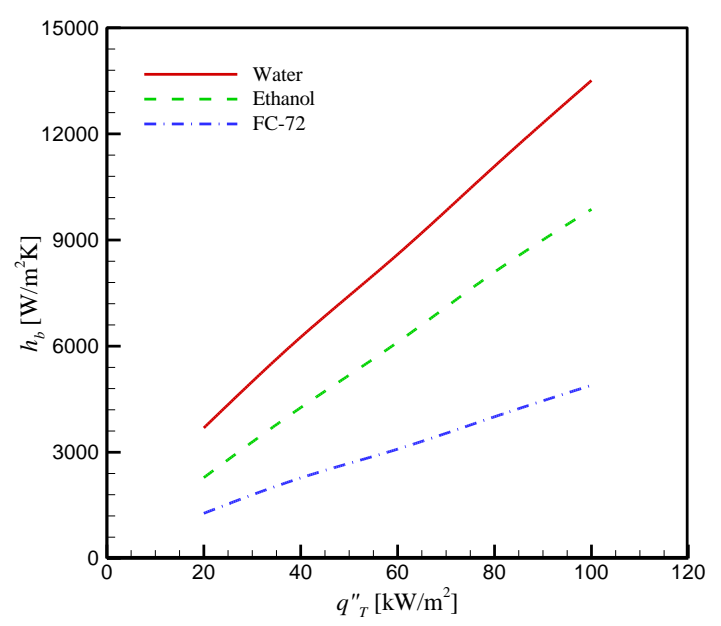

(a)

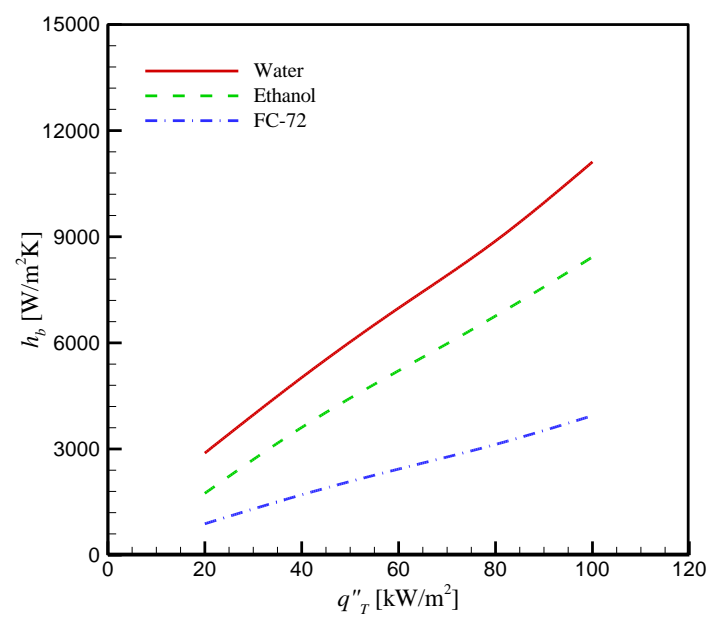

(c)

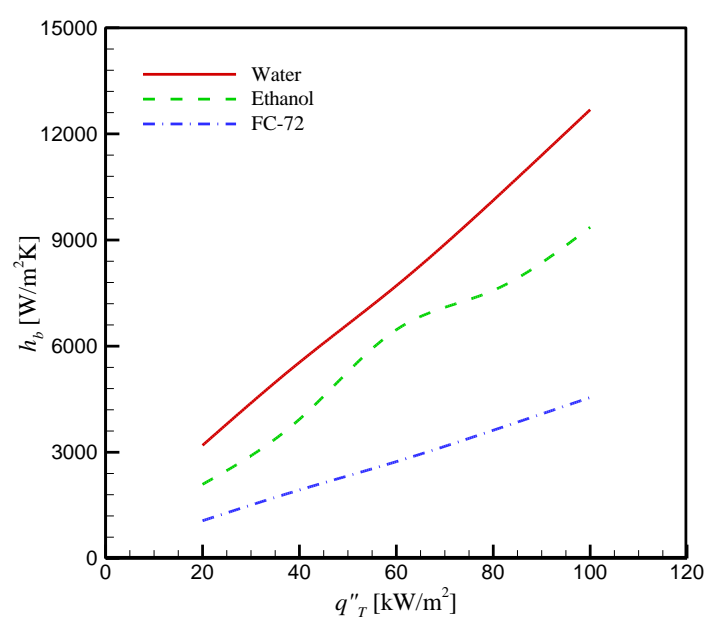

(b)

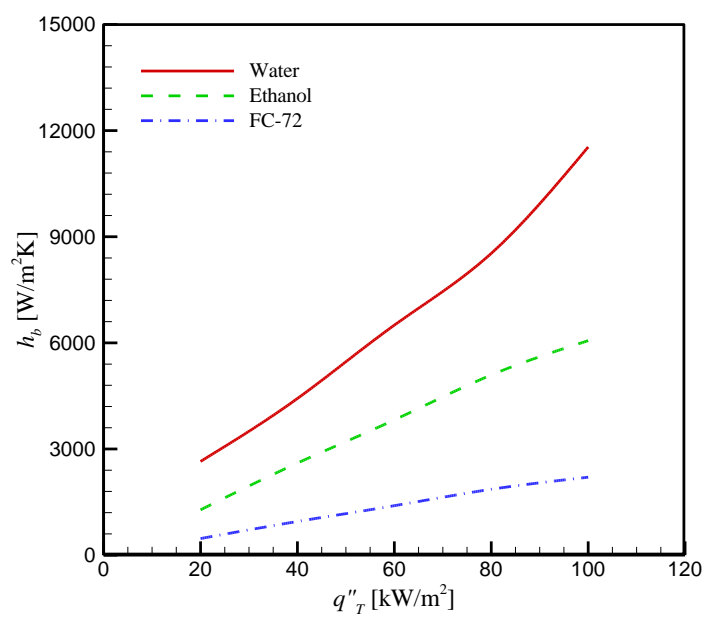

(d)

Fig. 8. Comparison between the variations of the heat transfer coefficient with wall heat flux for different working fluids at $q_{L}^{\prime \prime}=0 \mathrm{~kW} / \mathrm{m}^{2}$ : (a) $\theta=0^{\circ}$; (b) $\theta=30^{\circ}$; (c) $\theta=60^{\circ}$; and (d) $\theta=90^{\circ}$.

Figs. 9 and 10, present the similar results for the case $q_{L}^{\prime \prime}=90 \mathrm{~kW} / \mathrm{m}^{2}$. The trends of variations in the wall super heat level and boiling heat transfer coefficient are similar to those of Figs. 7 and 8, but a bit lower in the boiling heat transfer coefficient. It is due to the fact that the produced vapour from the bottom tube goes upward and prevent the access of the environment liquid to the top tube surface. An interesting result obtained for the inclination angle of $\theta=60^{\circ}$, where the effects of the 
produced vapour from the bottom surface and inclination angle cause an decrease in the boiling heat transfer coefficient for water as the working fluid.

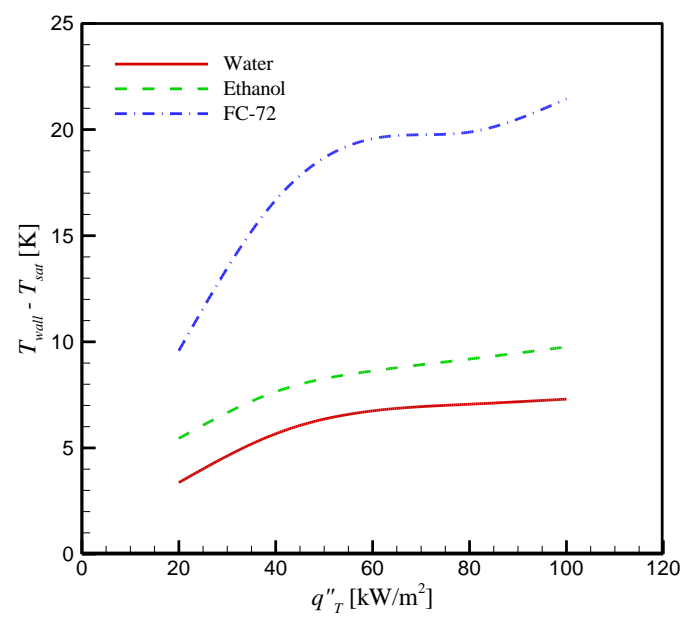

(a)

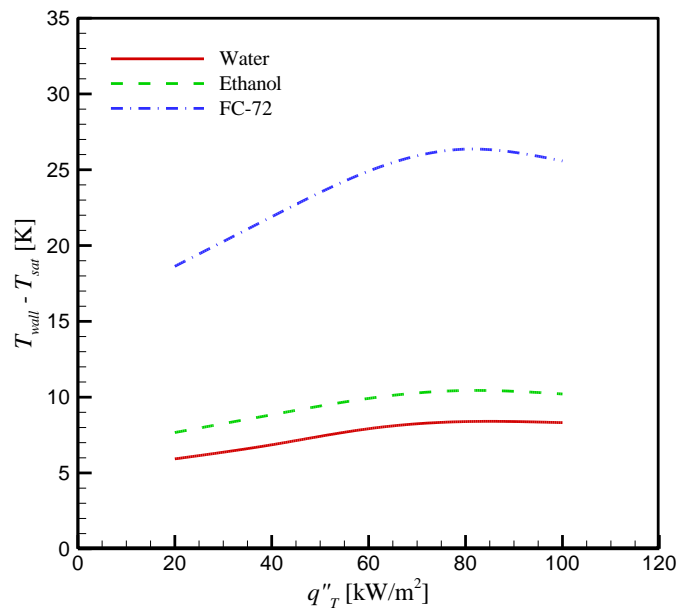

(c)

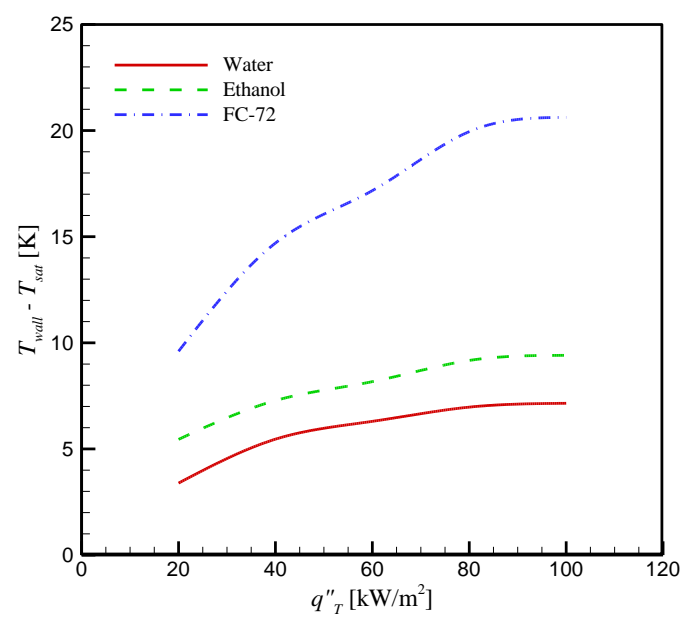

(b)

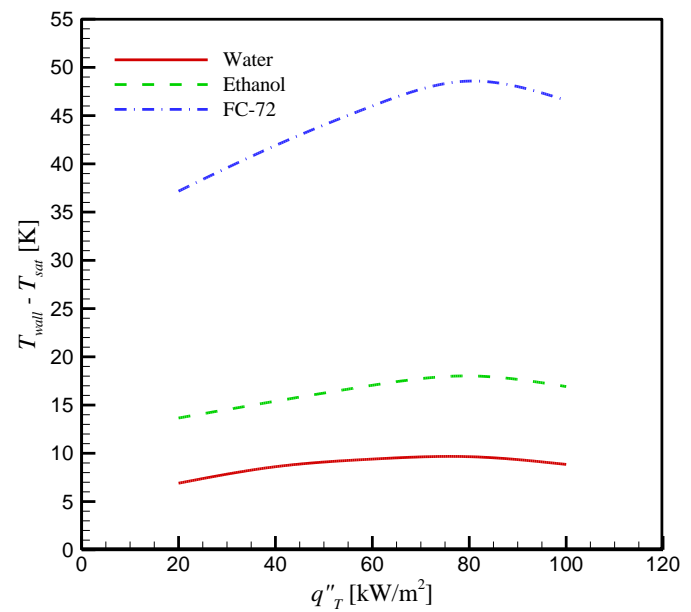

(d)

Fig. 9. Comparison between the variations of the wall superheat level with wall heat flux for different working fluids at $q_{L}^{\prime \prime}=90 \mathrm{~kW} / \mathrm{m}^{2}$ : (a) $\theta=0^{\circ}$; (b) $\theta=30^{\circ}$; (c) $\theta=60^{\circ}$; and (d) $\theta=90^{\circ}$. 


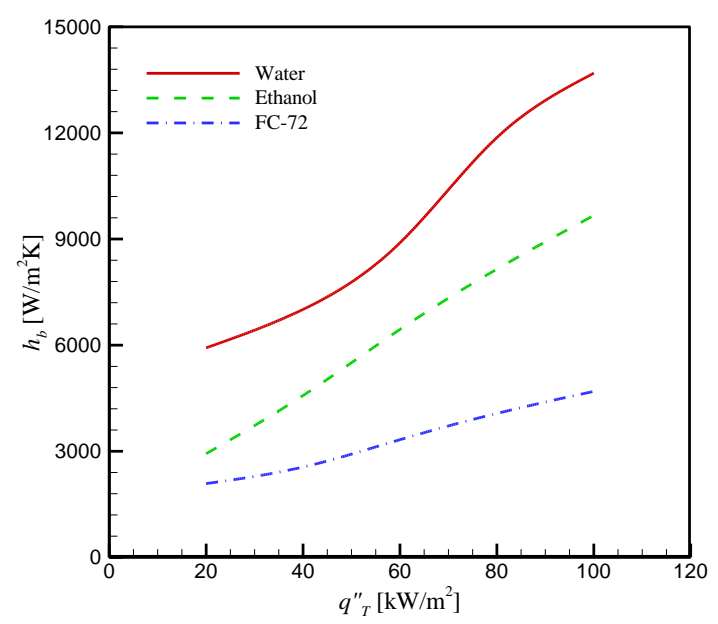

(a)

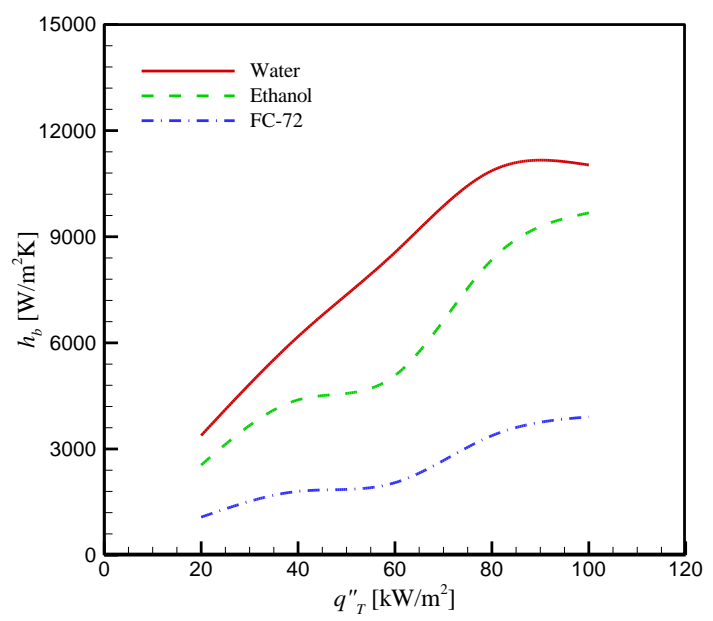

(c)

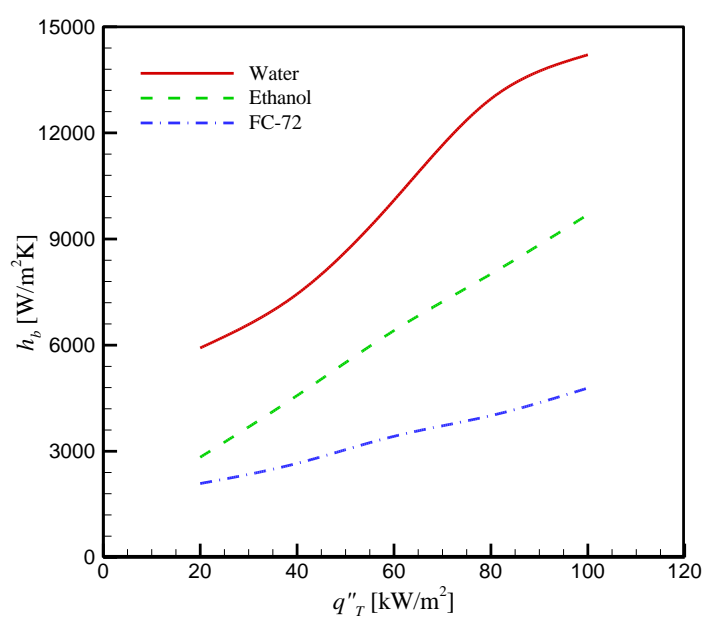

(b)

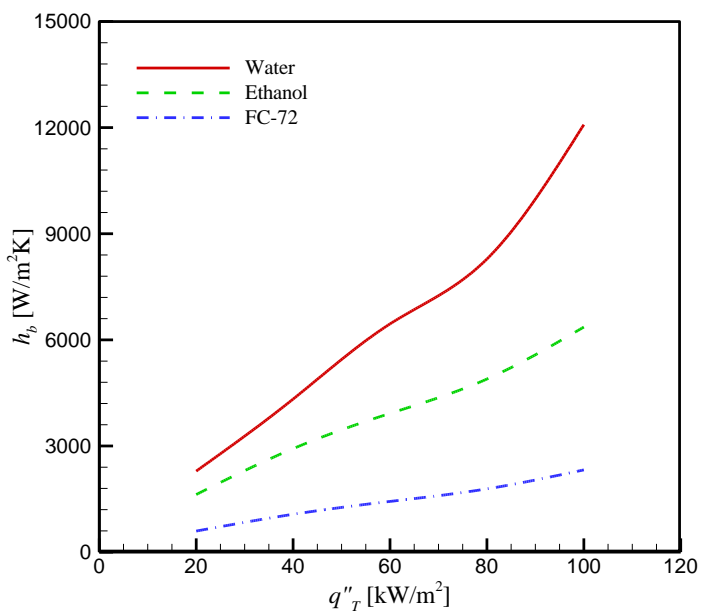

(d)

Fig. 10 Comparison between the variations of the heat transfer coefficient with wall heat flux for different working fluids at $q_{L}^{\prime \prime}=90 \mathrm{~kW} / \mathrm{m}^{2}$ : (a) $\theta=0^{\circ}$; (b) $\theta=30^{\circ}$; (c) $\theta=60^{\circ}$; and (d) $\theta=90^{\circ}$.

The effect of boiling fluid is further explored in Figs. 11 and 12, where the contours of vapour volume fraction under various thermal conditions are given for water, ethanol and FC-72. In Fig. 11 the contours of vapour volume fraction at $\theta=30^{\circ}, q_{L}^{\prime \prime}=0 \mathrm{~kW} / \mathrm{m}^{2}$ and for three working fluids are depicted. It is obvious that with the increase of the top tube heat flux the produced vapour, which is shown as a fog, increases. Another point is that the volume fraction of the water vapour 


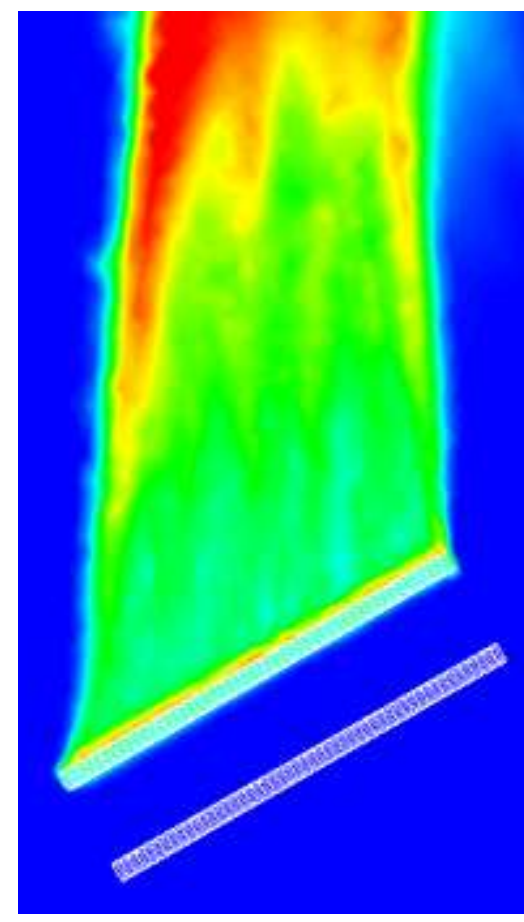

(a)

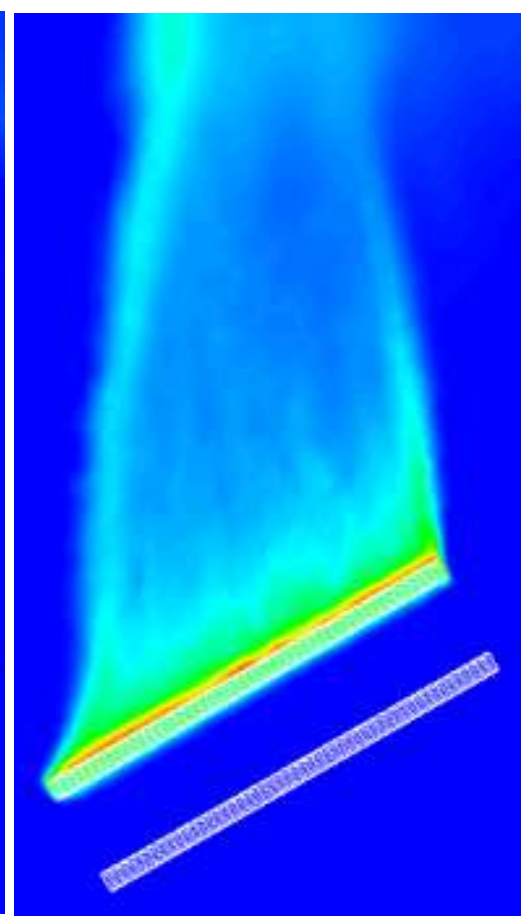

(b)

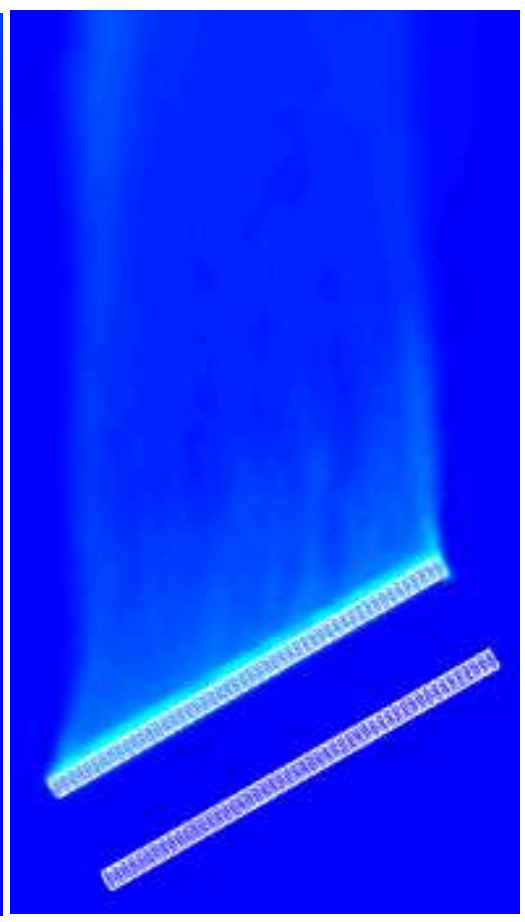

(c)

$q_{T}^{\prime \prime}=20 \mathrm{~kW} / \mathrm{m}^{2}$ (contour levels: 0.0 to 0.01 )

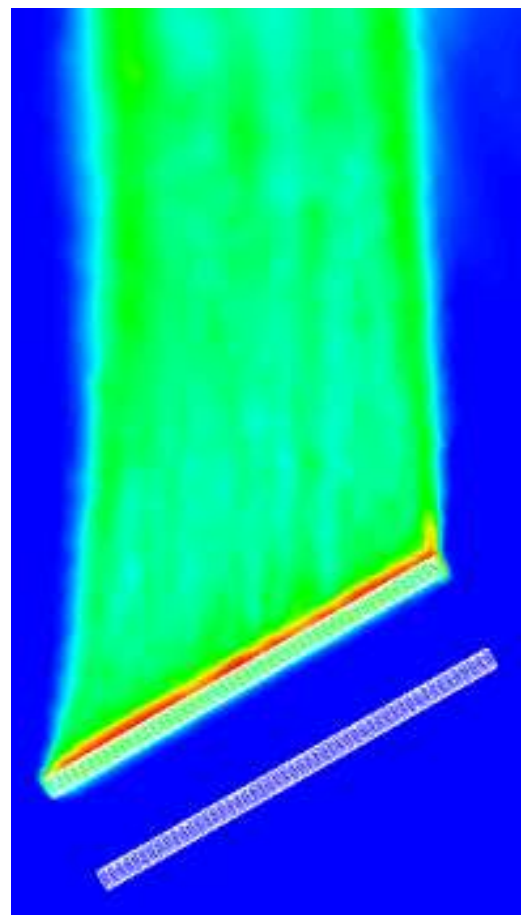

(a)

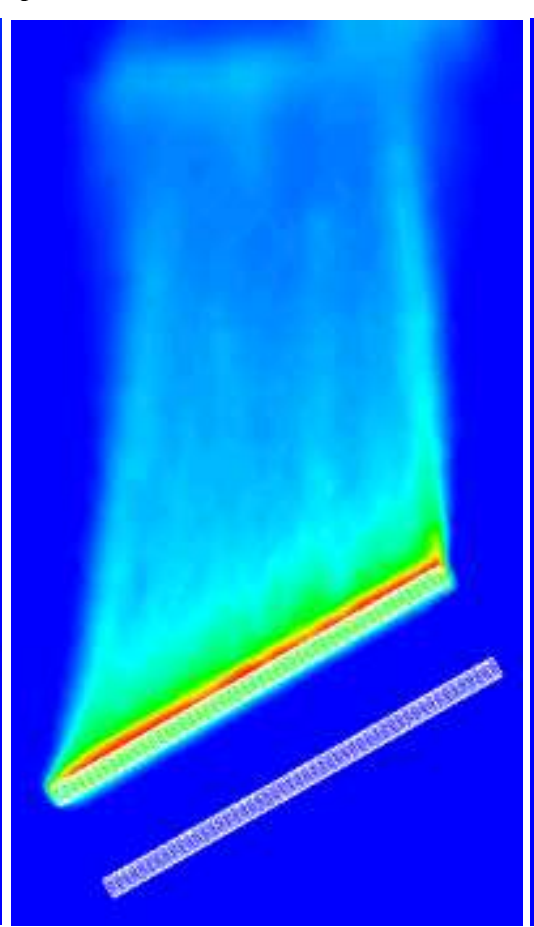

(b)

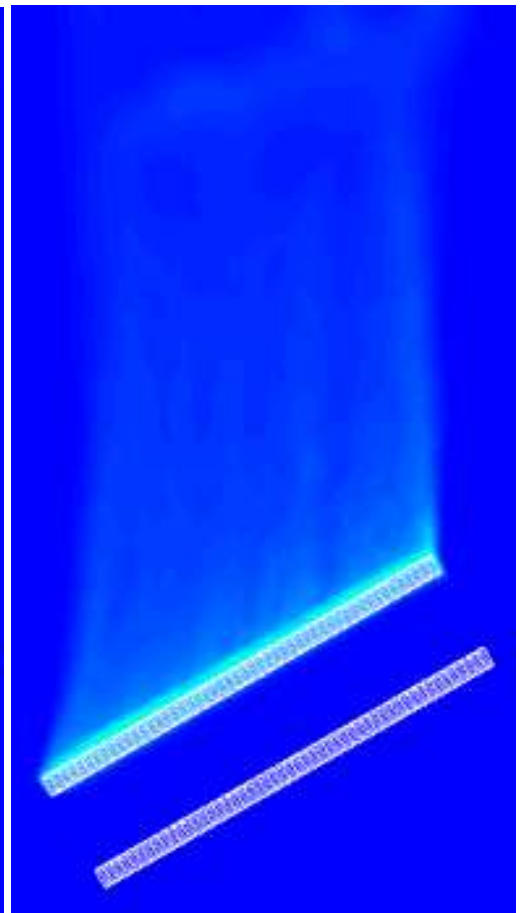

(c)

$q_{T}^{\prime \prime}=100 \mathrm{~kW} / \mathrm{m}^{2}$ (contour levels: 0.0 to 0.02 )

Fig. 11 Contours of vapour volume fraction at $\theta=30^{\circ}$ and $q_{L}^{\prime \prime}=0 \mathrm{~kW} / \mathrm{m}^{2}$ : (a) Water;

(b) ethanol; and (c) FC-72. 


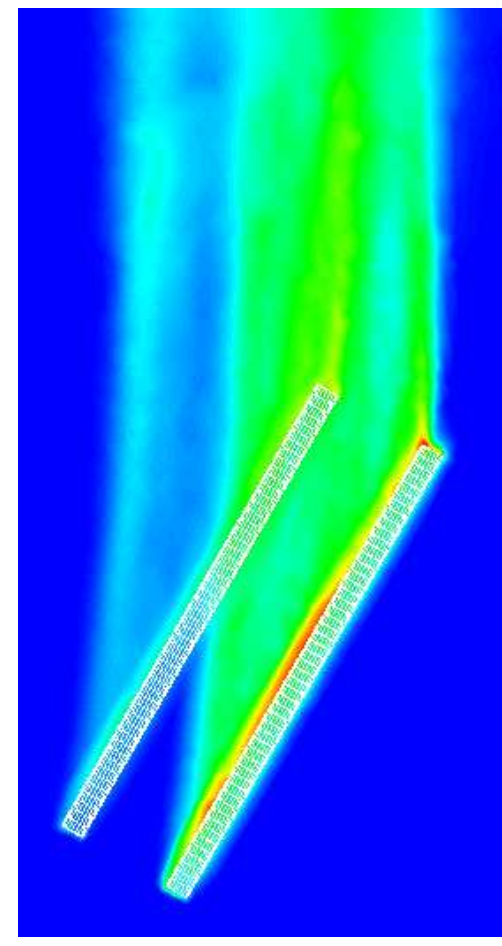

(a)

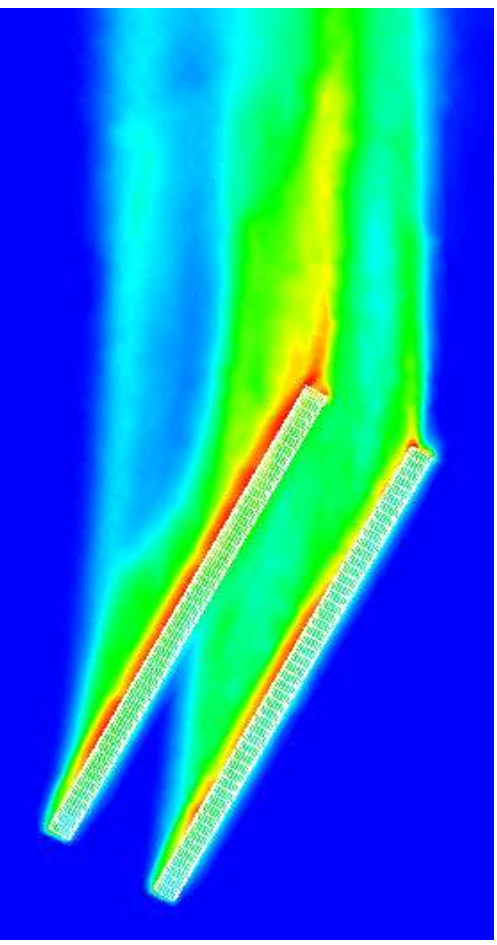

(a)

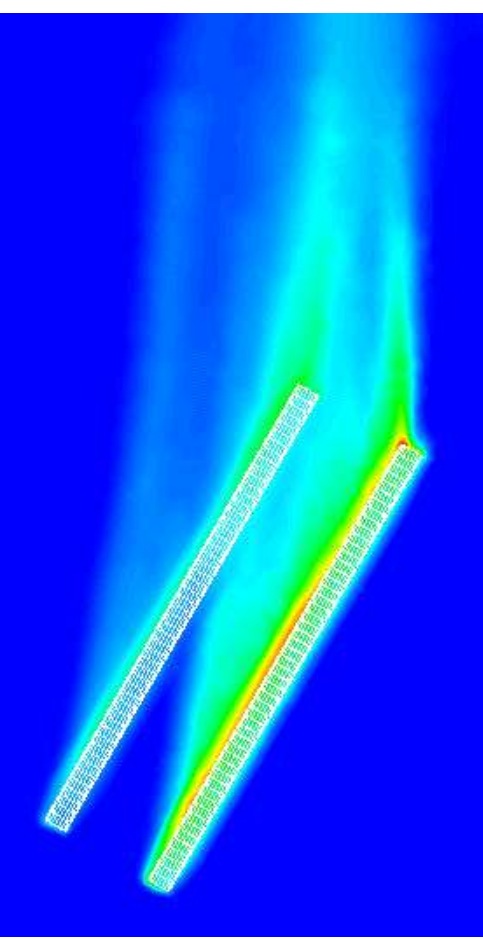

(b)

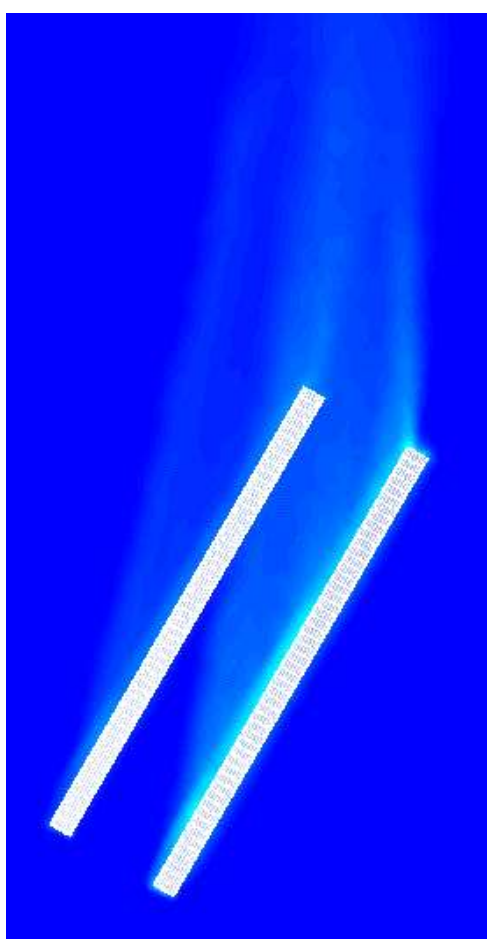

(c)

$q_{T}^{\prime \prime}=20 \mathrm{~kW} / \mathrm{m}^{2}$ (contour levels: 0.0 to 0.025 )

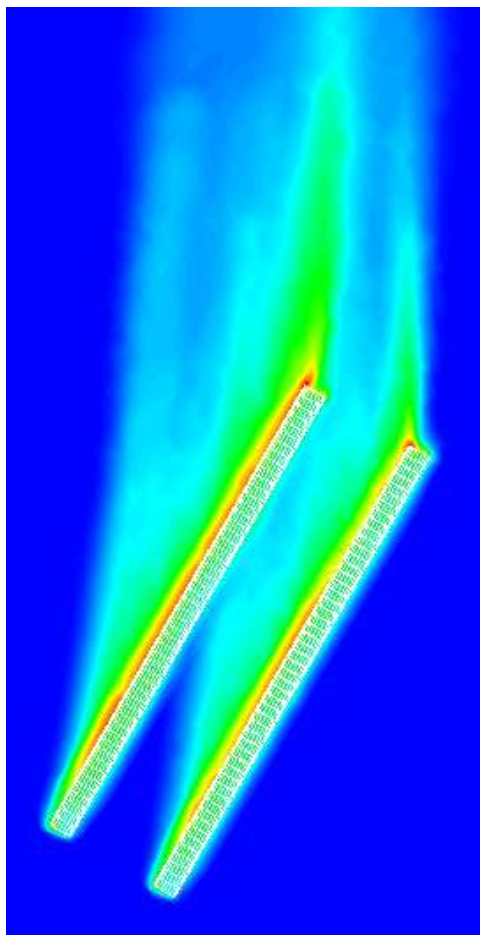

(b)

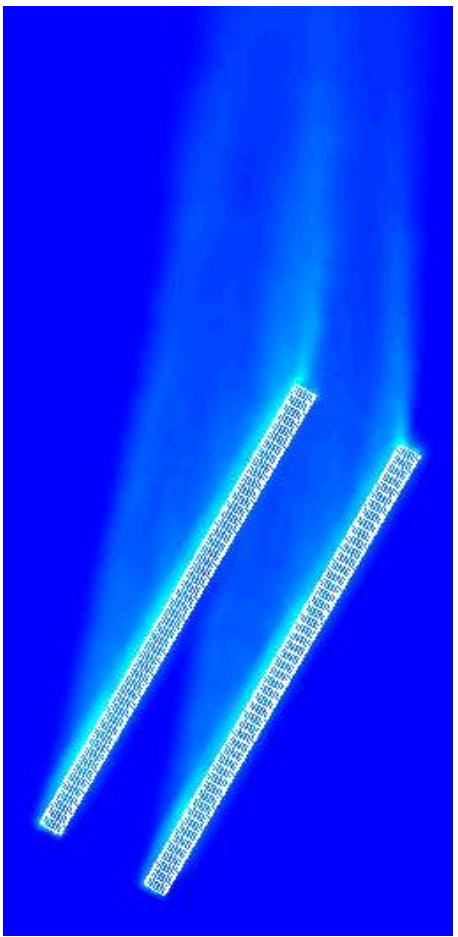

(c)

$q_{T}^{\prime \prime}=100 \mathrm{~kW} / \mathrm{m}^{2}$ (contour levels: 0.0 to 0.01 )

Fig. 12. Contours of vapour volume fraction at $\theta=60^{\circ}$ and $q_{L}^{\prime \prime}=90 \mathrm{~kW} / \mathrm{m}^{2}$ : (a) Water;

(b) ethanol; and (c) FC-72. 
is more than ethanol and FC-72. This means that at the prescribed operating conditions the water has the higher heat transfer coefficient and consequently higher mass transfer rate and produced vapour. Fig. 12 shows the similar results when the bottom tube is activated $\left(q_{L}^{\prime \prime}=90 \mathrm{~kW} / \mathrm{m}^{2}\right)$ and for $\theta=60^{\circ}$. It can be seen that almost half of the top tube is affected by the bottom one, which causes a decrease in the boiling heat transfer coefficient in the top tube. Furthermore, similar to the case shown in Fig. 11, the volume fractions are higher for water.

Fig. 13 shows the boiling heat transfer coefficient enhancement for different heat flux conditions, working fluids and inclination angles. It is defined as the ratio of the boiling heat transfer coefficient $\left(h_{b}\right)$ for the top tube in a bundle with lower tube activated to that for the same tube activated alone in the bundle [16]. It can be clearly seen that the enhancement of the heat transfer coefficient is higher at lower values of $q_{T}^{\prime \prime}$, and gradually decreases with the increate of the heat flux. This trend is valid for all working fluids and inclination angle. However for $\theta=90^{\circ}$ the effect of bottom tube is very trivial. It can be attributed to the fact that with increase of $q_{T}^{\prime \prime}$ the assisting effect of the bottom tube on increasing of the velocity and turbulence diminishes. Furthermore, the results show that with increase of tube inclination angle the boiling heat transfer enhancement decreases. The reason for such behaviour is that with increase of the tube inclination angle the affected area by the bottom tube decreases. Finally, it can be concluded that the change of the working fluid has no considerable effect on the enhancement of boiling heat transfer coefficient. 


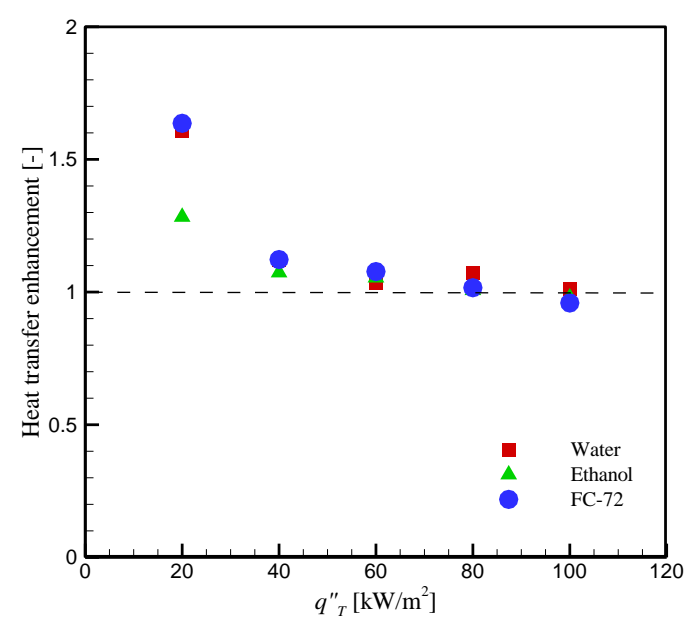

(a)

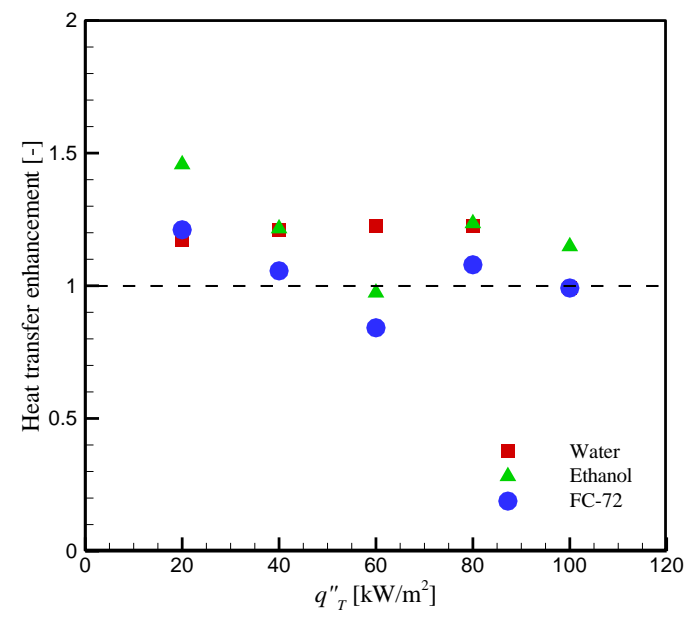

(c)

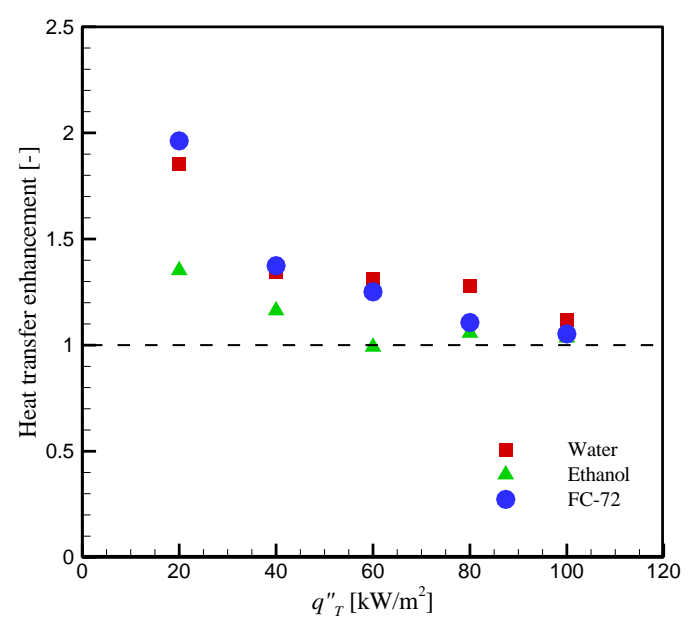

(b)

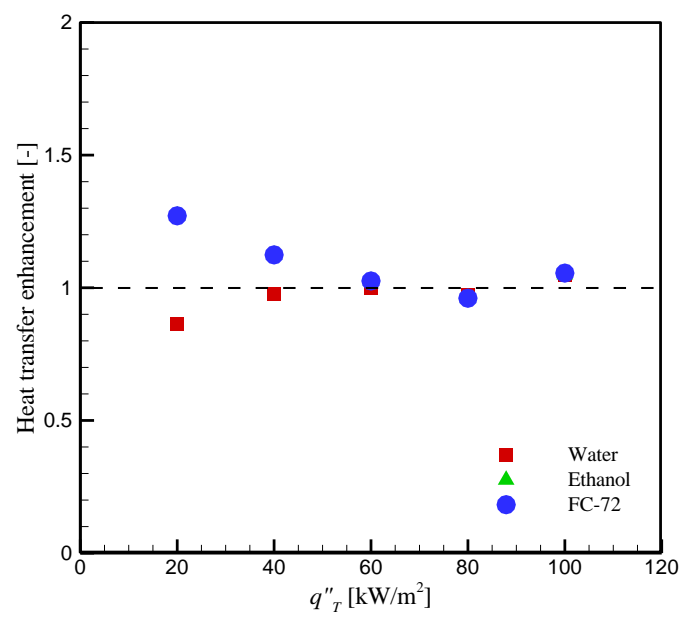

(d)

Fig. 13. Enhancement of the boiling heat transfer coefficient: (a) $\theta=0^{\circ}$; (b) $\theta=30^{\circ}$; (c) $\theta=60^{\circ}$; and (d) $\theta=90^{\circ}$.

\section{Conclusions}

In this study, pool boiling on smooth, vertically aligned tandem tubes is simulated using an Eulerian-Eulerian description of the two-phase boiling flow. We demonstrated that adapting an RPI boiling model could accurately predict the pool boiling curve and heat transfer coefficient via comparison to experimental measurements. The effect of boiling liquid properties is also investigated using water, ethanol and FC-72 as working fluids. We concluded that water had the 
highest and FC-72 the lowest heat transfer coefficient for all the simulated cases. Moreover, we showed that any increase in the inclination angle of the heated tubes decreased the intensity of the pool boiling heat transfer. It was observed that, as the lower tube became thermally active, the pool boiling heat transfer increased the upper tube. The results also showed that the enhancement of the boiling heat transfer coefficient is more considerable at lower values of $q_{T}^{\prime \prime}$ and tube inclination angles.

This work can be further extended in the future. Due to development of tubes with enhanced surfaces, the future works will focus on the effect of tube roughness on the boiling heat transfer coefficient. Furthermore, the structure of tube array would affect the velocity field around the tubes and needs to be investigated.

\section{References}

[1] G. Ribatski, J. M. S. Jabardo, E. F. da Silva, Modeling and experimental study of nucleate boiling on a vertical array of horizontal plain tubes, Exp. Therm. Fluid Sci. 32 (2008) 15301537.

[2] A. Swain, M. K. Das, A review on saturated boiling of liquids on tube bundles, Heat Mass Transf. 50 (2014) 617-637.

[3] A. Swain, R.L. Mohanty, M.K. Das, Pool boiling of distilled water over tube bundle with variable heat flux, Heat Mass Transf. 53 (2017) 2487-2495.

[4] K. Stephan, M. Abdelsalam, Heat transfer correlations for natural convection boiling, Int. J. Heat Mass Transf. 23 (1980) 73-87.

[5] D. Gorenflo, Pool boiling, VDI Heat Atlas, Chap. Ha, VDI Verlag, Dusseldorf, Ha1-Ha-25, 1994. 
[6] L. Aprin, P. Mercier, L. Tadrist, Local heat transfer analysis for boiling of hydrocarbons in complex geometries: A new approach for heat transfer prediction in staggered tube bundle, Int. J. Heat Mass Transf. 54 (2011) 4203-4219.

[7] E. Gorgy, S. Eckels, Local heat transfer coefficient for pool boiling of R-134a and R-123 on smooth and enhanced tubes, Int. J. Heat Mass Transf. 55 (2012) 3021-3028.

[8] L. H. Chien, R. Webb, A parametric study of nucleate boiling on structured surfaces, Part I: Effect of tunnel dimensions, J. Heat Transf. 120 (1998) 1042.

[9] L. H. Chien, R. Webb, A parametric study of nucleate boiling on structured surfaces, part II: Effect of pore diameter and pore pitch, J. Heat Transf. 120 (1998) 1049.

[10] A. Gupta, R. Kumar, V. Kumar, Nucleate pool boiling heat transfer over a bundle of vertical tubes, Int. Comm. Heat Mass Transf. 37 (2010) 178-181.

[11] G. Ribatski, J. R. Thome, Two-phase flow and heat transfer across horizontal tube bundles-a review, Heat Transfer Eng. 28 (2007) 508-524.

[12] K. Krasowski, J. Cieslinski, Nucleate pool boiling heat transfer from small horizontal smooth tube bundles, Transactions of the Institute of Fluid-Flow Machinery, 123 (2011) 85-98.

[13] M. G. Kang, Local pool boiling coefficients on horizontal tubes, J. Mech. Sci. Tech. 19 (2005) 860-869.

[14] M. G. Kang, Pool boiling heat transfer on tandem tubes in vertical alignment, Int. J. Heat Mass Transf. 87 (2015) 138-144.

[15] M. G. Kang, Effect of elevation angle on pool boiling heat transfer of tandem tubes, Int. J. Heat Mass Transf. 85 (2015) 918-923.

[16] M. G. Kang, Pool boiling heat transfer from an inclined tube bundle, Int. J. Heat Mass Transf. 101 (2016) 445-451. 
[17] A. Ustinov, V. Ustinov, J. Mitrovic, Pool boiling heat transfer of tandem tubes provided with the novel micro-structures, Int. J. Heat Mass Transf., 32 (2011) 777-784.

[18] S. N. Shoghl, M. Bahrami, M. K. Moraveji, Experimental investigation and CFD modeling of the dynamics of bubbles in nanofluid pool boiling, Int. Comm. Heat Mass Transf. 58 (2014) 12-24.

[19] Y. Liu, T. Olewski, L. N. Vechot, Modeling of a cryogenic liquid pool boiling by CFD simulation, J. Loss Prev. Process Ind. 35 (2015) 125-134.

[20] Y. Sato, B. Niceno, Nucleate pool boiling simulations using the interface tracking method: Boiling regime from discrete bubble to vapour mushroom region, Int. J. Heat Mass Transf. 105 (2017) 505-524.

[21] Z. Xiaobin, X. Wei, C. Jianye, W. Yuchen, K. Tang, CFD simulations and experimental verification on nucleate pool boiling of liquid nitrogen, Phys. Procedia 67 (2015) 569-575.

[22] J. Gu, Q. Wang, Y. Wu, J. Lyu, S. Li, W. Yao, Modeling of subcooled boiling by extending the RPI wall boiling model to ultra-high pressure conditions, Appl. Therm. Eng. 124 (2017) 571-584.

[23] M. Lemmertm, L. M. Chawla, Influence of flow velocity on surface boiling heat transfer coefficient in Heat Transfer in Boiling, Academic Press and Hemisphere, 1977.

[24] H. C. Unal, Maximum bubble diameter, maximum bubble-growth time and bubble-growth rate during the subcooled nucleate flow boiling of water up to $17.7 \mathrm{MN} / \mathrm{m}^{2}$, Int. J. Heat Mass Transf. 19 (1976) 643-649.

[25] R. Cole, A Photographic Study of Pool Boiling in the Region of the Critical Heat Flux, AIChE J. 6 (1960) 533-542. 
[26] R. L. Mohanty, M.K. Das, A critical review on bubble dynamics parameters influencing boiling heat transfer, Ren. Sus. Energ. Rev. 78 (2017) 466-494.

[27] N. Minocha, J. B. Joshi, A.K. Nayak, P. K. Vijayan, 3D CFD simulation of passive decay heat removal system under boiling conditions: Role of bubble sliding motion on inclined heated tubes, Chem. Eng. Sci. 145 (2016) 245-265.

[28] S.M.A. Noori Rahim Abadi, J. P. Meyer, Numerical investigation into the inclination effect on conjugate pool boiling and the condensation of steam in a passive heat removal system, Int. J. Heat Mass Transfer (2017), https://doi.org/10.1016/j.ijheatmasstransfer.2017.12.093

[29] G. Giustini, S. P. Walker, Y. Sato, B. Niceno, Computational Fluid Dynamics Analysis of the Transient Cooling of the Boiling Surface at Bubble Departure, J. Heat Transf. 139 (2017) 091501-15.

[30] T. Sun, W. Li, Three-dimensional numerical simulation of nucleate boiling bubble by lattice Boltzmann method, Comput. Fluids 88 (2013) 400-409.

[31] G. Huber, S. Tanguy, M. Sagan, C. Colin, Direct numerical simulation of nucleate pool boiling at large microscopic contact angle and moderate Jakob number, Int. J. Heat Mass Transf. 113 (2017) 662-682.

[32] X. Li, Y. Yuan, J. Tu, A parametric study of the heat flux partitioning model for nucleate boiling of nanofluids, Int. J. Therm. Sci. 98 (2015) 42-50.

[33] H. Ma, W. Cai, J. Chen, Y. Yao, Y. Jiang, Numerical investigation on saturated boiling and heat transfer correlations in a vertical rectangular minichannel, Int. J. Therm. Sci. 98 (2016) 285-299.

[34] G. H. Yeoh, J. Tu, Computational Techniques for Multi-Phases Flows Elsevier, UK, 2010. 
[35] A. R. Avetissian, G. A. Philippov, L. I. Zaichik, Effects of turbulence and inlet moisture on two-phase spontaneously condensing flows in transonic nozzles, Int. J. Heat Mass Transf. 51 (2008) 4195-4203.

[36] A. R. Avetissian, G. A. Philippov, L. I. Zaichik, The effect of turbulence on spontaneously condensing wet-steam flow, Nuc. Eng. Des. 235 (2005) 1215-1223.

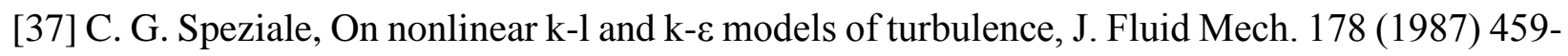
475.

[38] T. B. Gatski, C. G. Speziale, On explicit algebraic stress models for complex turbulent flows, J. Fluid Mech. 254 (1993) 59-78.

[39] W. Yao, C. Morel, Volumetric area prediction in upward bubbly two-phase flow, Int. J. Heat Mass Transf. 47 (2004) 307-328.

[40] R. Clift, J. R. Grace, M. E. Weber, Bubbles, Drops and Particles Academic Press, 1978.

[41] A. Tomiyama, Struggle with computational bubble dynamics, Third International Conference on Multiphase Flow, Lyon, France, June 8-12, 1998.

[42] S. P. Antal, R. T. Lahey, J. E. Flaherty, Analysis of phase distribution in fully developed laminar bubbly two-phase flow, Int. J. Multi. Flow 17 (1991) 635-652.

[43] A. D. Burns, T. Frank, I. Hamill, J. M. Shi, The Favre averaged drag model for turbulent dispersion in Eulerian multi-phase flows, Fifth International Conference on Multiphase Flow, ICMF-2004, Yokohama, Japan, 2004.

[44] N. Kurul, M. Z. Podowski, On the modeling of multidimensional effects in boiling channels, Proceedings of the 27th National Heat Transfer Conference, Minneapolis, Minnesota, USA, 1991. 
[45] V. H. Del Valle, D. B. R. Kenning, Sub-cooled flow boiling at high heat flux, Int. J. Heat Mass Transf. 28 (1985) 1907-1920.

[46] W. E. Ranz, W. R. Marshall, Jr., Vaporation from Drops, Part I, Chem. Eng. Prog. 48 (1952) 141-146.

[47] S. Muzaferija, M. Peric, P. Sames, T. Schellin. A Two-Fluid Navier-Stokes Solver to Simulate Water Entrt, In Proc 22nd Symposium on Naval Hydrodynamics, Washington, DC. (1998) 277-289.

[48] K. H. Ardron, G. Giustini, S. P. Walker, Prediction of dynamic contact angles and bubble departure diameters in pool boiling using equilibrium thermodynamics, Int. J. Heat Mass Transf. 114 (2017) 1274-1294.

[49] J. Kim, S. Jun, R. Laksnarain, S. M. You, Effect of surface roughness on pool boiling heat transfer at a heated surface having moderate wettability, Int. J. Heat Mass Transf. 101 (2016) 992-1002.

[50] A. Stojanović, V. Stevanović, M. Petrović, D. Živković, B. Stanković, Numerical study of heat transfer during nucleate pool boiling, Advanc. Technol. 5 (2016) 73-80.

[51] E. Strak, R. Pastuszko, The effect of Bond number on pool boiling for mini-fin surfaces and different working fluids, EPJ Web of Conferences, 114 (2016) 02113. 